\title{
Montículos arqueológicos, actividades y modos de habitar. Vivienda y uso del espacio doméstico en Santiago del Estero (tierras bajas de Argentina)
}

\author{
Archaeological mounds, activities and ways to inhabit. Dwellings \\ and domestic space use in Santiago del Estero (Argentine lowlands)
}

\author{
Constanza Taboada \\ Instituto Superior de Estudios Sociales (ISES) del Consejo Nacional de Investigaciones Científicas \\ y Técnicas de la República Argentina (CONICET) / Instituto de Arqueología y Museo (IAM) de la Universidad Nacional de Tucumán (UNT) \\ e-mail: constanzataboada@gmail.com
}

\section{RESUMEN}

Este artículo aborda la definición del espacio habitacional de las poblaciones indígenas que vivieron en la llanura de Santiago del Estero (Argentina) y su vinculación con los montículos característicos de la región. Parte de trabajos arqueológicos de campo y pone en juego una estrategia teórico-metodológica que apunta a superar las limitaciones de una arquitectura perecedera. Como resultado se identificó un ámbito doméstico techado, con el primer registro para la región de un techo de torta y un piso posiblemente preparado. En articulación con la reinterpretación de datos bibliográficos, se definieron situaciones diferenciadas en cuanto a actividades, construcciones y modos de habitar, que habilitan una nueva lectura sobre la diversidad y características de las poblaciones de la región. Los casos analizados amplían el conocimiento de la diversidad y distribución de las construcciones monticulares de las tierras bajas de Sudamérica, y aportan elementos sobre arquitectura doméstica, poco estudiada para los mismos.
\end{abstract}

Palabras clave: arqueología de unidades domésticas; arquitectura; estratigrafía; prehispánico; colonial; tierras bajas sudamericanas.

\section{ABSTRACT}

This paper intends to provide information to a subject which has not been studied yet -the aboriginal domestic dwellings in Santiago del Estero plain, Argentina. For that reason we have tried to relate this issue to that of the typical mounds of the area, based on archaeological studies. We propose a theoretical model and methodological strategies to overcome the limitations imposed by a perishable architecture. This allowed us to identify the first signs of a covered area with a floor. With the reinterpretation of bibliographic data we were able to define different situations about activities, construction and lifestyles that permitted us to have a new look on the population diversity and characteristics. The cases analyzed also broaden the knowledge on diversity and distribution of mound structures in Southamerican lowlands and provide elements on domestic architecture, that has been little analyzed for these structures.

Keywords: household archaeology; architecture; stratigraphy; prehispanic; colonial; South American lowlands.

Recibido: 31-08-2015. Aceptado: 19-04-2016.

Cómo citar este artículo / Citation

Taboada, C. 2016: "Montículos arqueológicos, actividades y modos de habitar. Vivienda y uso del espacio doméstico en Santiago del Estero (tierras bajas de Argentina)", Arqueología de la Arquitectura, 13: e040. doi: http://dx.doi.org/10.3989/arq.arqt.2016.003

\section{Copyright}

(c) 2016 CSIC. Este es un artículo de acceso abierto distribuido bajo los términos de una licencia de uso y distribución Creative Commons Attribution (CC-by) España 3.0. 


\section{INTRODUCCIÓN Y PLANTEO DE LA PROBLEMÁTICA}

En gran parte de la provincia de Santiago del Estero (tierras bajas de Argentina) (Fig. 1) se registran montículos arqueológicos cuyo origen y significación conductual en relación a los espacios de habitación del pasado presentan varios interrogantes. Este tipo de configuración, con variantes estructurales y culturales, es característico de las poblaciones de las tierras bajas sudamericanas y su estudio ha ido cobrando creciente importancia en concordancia con el papel activo que se les ha ido reconociendo a dichos grupos en su modelación (Ochoa, Rostain y Salazar 1997; Barreto 2006; Bonomo, Politis y Gianotti 2011; Rostain 2011; Prümers y Jaimes Betancourt 2014, etc.). A pesar de participar de esta problemática macro-regional, los montículos de Santiago del Estero no han sido considerados en relación a ella. Esto se debe, posiblemente, a que su estudio casi no fue abordado luego de que, en la década del 30 del siglo XX, se generó una gran controversia en torno a su origen natural o antrópico (Wagner y Wagner 1934; Relaciones 1940). Posteriormente a ella, sólo abordó su estudio Ana María Lorandi (1974, 1978). Caracterizó sus aspectos de conjunto (orientación, disposición entre sí y en relación a otro tipo de formaciones) y en tanto unidades (variación de tamaños y composición cultural), preguntándose sobre las características que pudieron haber tenido las viviendas dada la ausencia de registros constructivos (Lorandi 2015). No obstante estos acercamientos, hasta ahora no se habían realizado estudios específicos sobre la arquitectura y el espacio doméstico de las poblaciones prehispánicas de la región ni sobre su relación con el problema de los montículos de Santiago del Estero.



Fig. 1. Mapa de Santiago del Estero con ubicación de los sitios arqueológicos analizados en el texto y referencias a las diferentes Situaciones (A, B, C) definidas en el artículo. Mapa realizado por la autora. 
Estas formaciones se organizan en el terreno según diversas disposiciones y en distinta asociación a relieves negativos, tradicionalmente referidos como "represas", además de a áreas bajas longitudinales, interpretadas como paleocauces y/o posibles canales antrópicos (Wagner y Wagner 1934; Reichlen 1940; Lorandi 1978; Ortiz y Fernández 2014). También diferentes actividades y configuraciones expuestas por las crónicas coloniales (Lorandi 2015) hacen legítimo preguntarse por el papel que las poblaciones pudieron desarrollar en la modelación del terreno en relación a diversas épocas y situaciones socioculturales. Hoy es posible pensar en una variedad de formaciones de diverso origen, uso y características, y afirmar que los montículos con restos arqueológicos de la llanura santiagueña son producto de procesos antrópicos y naturales combinados. Estos han generado un registro diferenciado que puede ser interrogado por la arqueología para intentar comprender los modos de instalarse y habitar de las poblaciones de la región. Sin embargo, la variedad de situaciones de la que parecen ser referentes fue quedando oculta tras la unificación en un mismo rótulo clasificatorio. Esta diversidad remite no solo a diferencias de orden natural y a diversos procesos de formación puestos de relieve en las discusiones pioneras, sino también en las actividades domésticas y en las construcciones desarrolladas, con implicancias para pensar usos y formas de vida particulares. En este último aspecto nos centramos en este trabajo, que consta de dos partes.

Primero, presentamos información desconocida para la región en términos de evidencias arquitectónicas y estratigráficas, a las que sumamos luego la relectura de datos aportados por otros autores para plantear diversas situaciones en torno a los montículos y su potencial para analizar la estructuración de los espacios domésticos y modos de habitar. Dado que la mayor parte de los trabajos que abordan la problemática de los montículos de las tierras bajas sudamericanas enfatiza el estudio de las secuencias culturales, funcionalidad, origen, monumentalidad y/o construcción del paisaje (Rostain 1999; Erickson 2000; Cabrera 2013; Gianotti y Bonomo 2013; Pestana 2013; entre otros), este artículo aporta una mirada centrada en el espacio doméstico y la arquitectura asociada como otro modo de acceder al análisis de formas de vida en torno a una práctica de instalación generalizada macroregionalmente.

\section{ANTECEDENTES. MONTÍCULOS, REPRESAS Y ESPACIO DOMÉSTICO EN LA ARQUEOLOGÍA SANTIAGUEÑA}

El primer acercamiento al tema fue la definición, realizada a principios del siglo XX por Emilio y Duncan Wagner (1934), de un patrón de montículos ("túmulos") en vinculación con depósitos de agua ("represas"). Los autores señalaron que los montículos se orientaban o bien "a modo de avenidas", o formando grupos, y presentaban dimensiones máximas de 25 a $50 \mathrm{~m}$ y hasta 3-4 $\mathrm{m}$ de alto (aunque nuestro registro remite a menores medidas, sobre todo en altura). El patrón fue presentado como producto de la acción antrópica, conformando yacimientos de diferentes extensiones, con cantidad y tamaños variados de montículos. Esta idea llevó a los autores a plantear que la región había sido habitada por una civilización muy avanzada y antigua de constructores de túmulos, evocando similitudes con los Mound Builders de EE.UU., algo que los miembros de la Sociedad Argentina de Antropología vieron como afrenta a una naciente ciencia argentina (Relaciones 1940; Martínez, Taboada y Auat 2011). Les objetaron la gran antigüedad, la función funeraria a la que el término "túmulo" aludía, y el origen construido de los montículos. Sin embargo, aunque ambiguamente expresado, los Wagner en realidad dijeron que los montículos de Santiago del Estero habían servido para el "asiento de habitaciones". El origen construido lo aplicaban al núcleo de base sobre el cual señalaban que se acumulaban a lo largo del tiempo desechos domésticos. Afirmaron, por su parte, que las represas habían sido "cavadas por la mano del hombre". En franca disputa y negando los que eran aciertos, sus opositores plantearon que estas estructuras no podían haber sido ejecutadas de forma planificada y que eran producto del aprovechamiento de la topografía natural (Frenguelli 1940), resultando planteos tan acotados como aquellos de los Wagner para entender la variabilidad de los procesos antrópicos en torno a ellas.

El análisis del ámbito doméstico quedó así subsumido en la confrontación sobre la génesis y antigüedad de los montículos. No hubo una problematización sobre cuáles podían ser los procesos, construcciones y actividades que habían dado lugar a los montículos, ni cómo se concebían los espacios de habitación. Tampoco se pensó la vinculación entre ellos en términos de actividades concretas, complementarias o diferenciadas. Los restos eran simplemente asignados a dos tipos de 
actividades: funerarias o domésticas. Sin embargo, algunos investigadores que por entonces tomaron cierta distancia de aquellas disputas, como Reichlen, von Hauenschild y Greslebin, aportaron datos y gráficos muy interesantes a partir de trabajos de campo en Santiago del Estero que se suman a información consignada por los Wagner, y muy posteriormente por Lorandi, para pensar actualmente el tema. Además, tres informes inéditos de von Hauenschild, Vellard y Lorandi ofrecen valiosas referencias no registradas en las publicaciones. Este corpus documental, analizado a la luz de una nueva problematización, de nuestras propias excavaciones, y de un modelo preliminar de uso del espacio habitacional nos llevó a re-conceptualizar en otros términos la información disponible y plantear la existencia de diferentes tipos de montículos y situaciones que analizaremos en este trabajo.

\section{MARCO TEÓRICO-METODOLÓGICO}

Como marco general nos encuadramos dentro de la llamada "Archaeology of Architecture" (sensu Steadman 1996), que se aboca al estudio del ambiente construido reconociéndole el papel que puede desarrollar en las relaciones sociales. Uno de sus fines es definir prácticas constructivas y formas de uso del espacio habitacional como un medio de acceder a las conductas cotidianas, modos de vida y organización social de los grupos domésticos en relación a sus marcos históricos de referencia y a una dinámica mutuamente constituida. Estos objetivos pueden ser abordados a partir de diversas orientaciones, según prioricen algún aspecto del accionar social o escala de abordaje. En nuestro caso, tomaremos como unidad de análisis el espacio doméstico (Household archaeology), buscando el contenido social detrás de las formas constructivas habitacionales. Su adopción como foco de análisis arqueológico tiene importantes fundamentos prácticos y teóricos que han sido señalados por Wilk y Rathje (1982). Entre ellos cabe destacar la posibilidad de establecer correlatos materiales del grupo doméstico. Dado que las actividades que desarrollan estos grupos generan residuos que se incorporan al registro arqueológico (Seymour y Schiffer 1987), se busca determinar el rango de actividades desarrolladas (por ejemplo, Netting, Wilk y Arnould 1984; Ashmore y Wilk 1988), indagando sobre su organización espacial y sus transformaciones en función de los cambios en la sociedad y en la economía. Este marco conceptual permite integrar el análisis de la arquitectura y el entorno construido, a los que se confiere un papel crucial dentro de dicho enfoque (por ejemplo, Adams 1983; Manzanilla 1986; Wilk y Ashmore 1988; Stanish 1989; Kent 1990; Blanton 1994) y en el cual damos particular relevancia a una concepción dinámica y cambiante de la arquitectura en relación a la historia de vida de las construcciones y a las necesidades del grupo doméstico (Schiffer 1972; Stevanovic 1997).

El estudio del registro arqueológico en los términos referidos se complementa, en este trabajo, con el análisis de expectativas surgidas de una observación actual de los modos locales tradicionales de construir y usar el espacio doméstico. Sin ser específicamente un estudio etnoarqueológico, nuestra estrategia de investigación asume sus fundamentos teóricos-metodológicos, que buscan "información sistemática acerca de la dimensión material de la conducta humana, tanto en el orden de los comportamientos y actividades concretas que los producen, como en el de las pautas de racionalidad subyacentes. Es una generadora de referentes análogos para la interpretación arqueológica y es una fuente de producción y contrastación de hipótesis y modelos acerca de cómo funcionan las sociedades" (Politis 2004: 92). De hecho, la argumentación analógica en el proceso de interpretación del registro arqueológico ha sido reconocida por gran cantidad de arqueólogos (Cfr. Hernando 1995; Sillar 2000; González 2003; Nielsen 2000; Politis 2004 , entre otros) y varios trabajos muestran su eficiencia para el análisis de espacios de actividad o habitación en diversos contextos de las tierras bajas sudamericanas con registro arqueológico arquitectónico perecible (Zeidler 1983; Borrero y Yacobaccio 1989; Politis 1996; Rostain 2006, etc.). Sin embargo, como ha marcado Nielsen (2001), es necesario proceder con precaución en la analogía con pueblos actuales, ya que el seguimiento de un modelo limitado conlleva el riesgo de ignorar usos y tipos funcionales de estructuras arquitectónicas no registrados en casos etnográficos. Como también señala este autor, una de las más importantes contribuciones de la arqueología de unidades domésticas, o incluso de la arqueología en general, radica en la posibilidad de estudiar configuraciones sociales completamente diferentes a aquellas que existen en el presente y que, de hecho, abordaremos también en este trabajo.

En nuestro caso, la legitimidad de integrar algunas implicancias derivadas de una observación actual se basa en la permanencia y determinación del ambiente local tanto en los materiales constructivos y en sus patrones de destrucción natural, como en los requerimientos de eficiencia, que generan pautas conductuales de uso del espacio 
que podrían ser análogos generales a los prehispánicos en función de similares condicionantes y necesidades. Sin embargo, como ha señalado Politis, el "grado de semejanza por sí mismo no garantiza de modo alguno la fortaleza de la argumentación ni la veracidad de los enunciados" (Politis 2004: 3). La metodología adoptada, entonces, "no pretende establecer relaciones no ambiguas y regularidades transculturales entre las conductas y sus derivados materiales, sino solo establecer relaciones de tipo general e intentar entender bajo qué condiciones sociales se puede esperar cierto tipo de registro arqueológico" (Politis 2004: 21-22).

Nuestra investigación apunta a los objetivos señalados precedentemente, planteándose como primera instancia para este artículo, la definición de pautas arquitectónicas y de uso del espacio doméstico y sus posibles variantes en tiempo, espacio y situaciones socio-históricas, dada la - hasta ahora - ausencia de tratamiento del tema para la llanura santiagueña. Sobre la base de un modelo básico de performances (Nielsen 1995, 2001; Taboada 2003), de la relectura bibliográfica, de nuevos trabajos de campo generados por nuestro proyecto, y de observaciones actuales sobre modos tradicionales de construir y organizar el espacio habitacional en la zona de trabajo de campo, consideramos viable un modelo de habitación prehispánico tardío —entre otros que también pudieron darse - similar al tradicional en su configuración y arquitectura, con posibles diferencias de instalación, disposición y resolución en función de tiempo, espacio y tradiciones culturales.

La comprobación — para al menos fines de la época prehispánica - de asentamientos estables, con agricultura e importantes vínculos interregionales, sumada a referencias coloniales sobre la existencia de viviendas de cierta estabilidad en torno de poblados organizados, habilita pensar en un modo de vida ligado a arquitectura permanente para dicho momento, pero no necesariamente para períodos anteriores u otras situaciones. En cualquier caso, la carencia de indicadores arqueológicos de construcciones, y las características ambientales de la región — ausencia absoluta de piedra y abundancia de árboles de maderas duras-, hacen presuponer edificaciones domésticas de tierra y madera, quizás similares a la construcción tradicional ${ }^{1}$ (Fig. 2), con necesidad de acondicionamiento periódico y con poca visibilidad directa en el registro arqueológico. Una cita sobre la vivienda de los sanavirones

\footnotetext{
La vivienda tradicional local se realiza con muros de quincha y/o palo a pique, posee techo de torta de barro sostenido por una estructura de madera y entramado de vegetales menores y cuenta con varios espacios discontinuos funcionalmente diferenciados (Cfr. Di Lullo y Garay 1969).
}

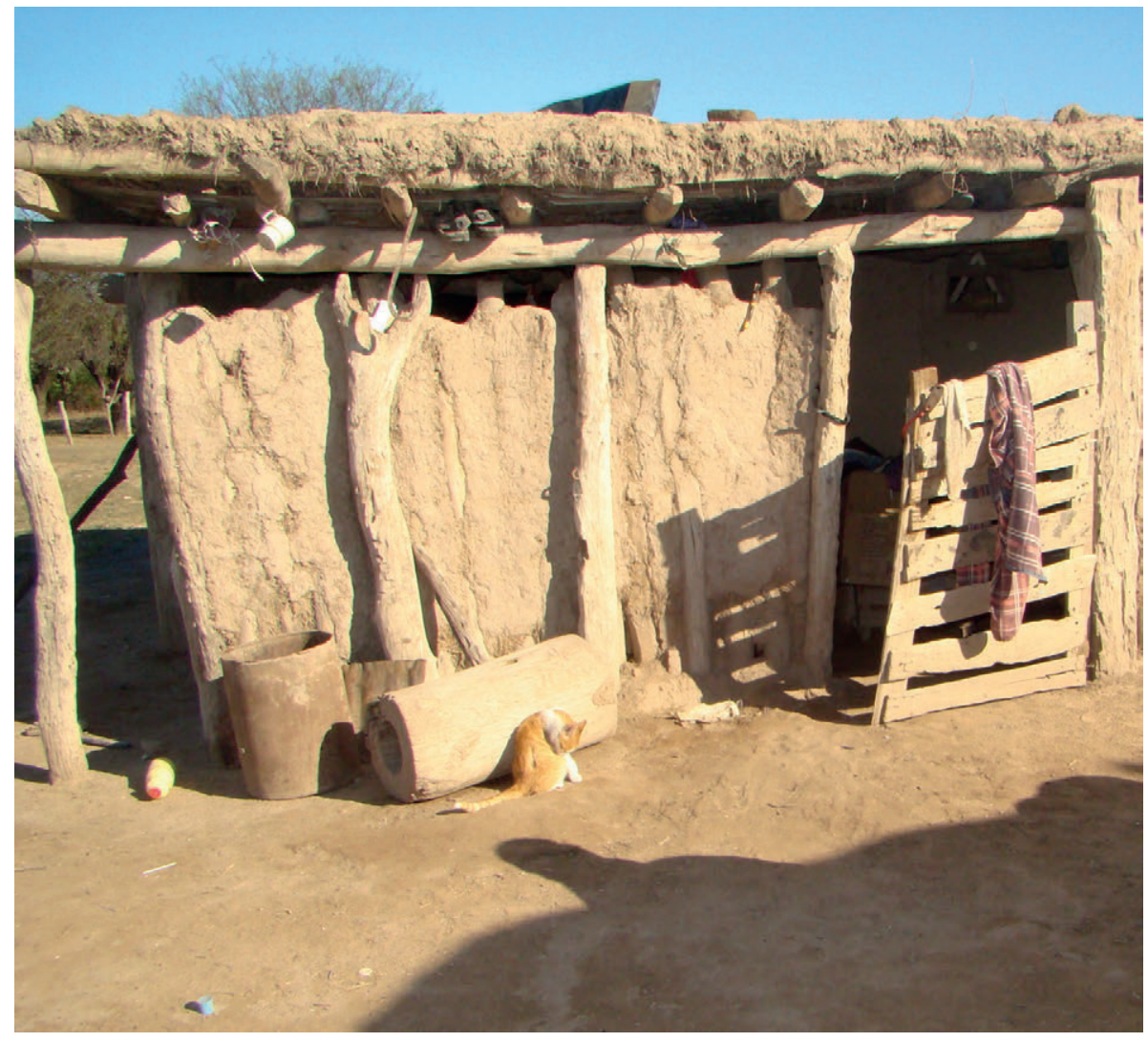

Fig. 2. Habitación realizada con material y técnica tradicional de palo a pique. Vivienda de la Familia Silva. Fotografía de la autora. 


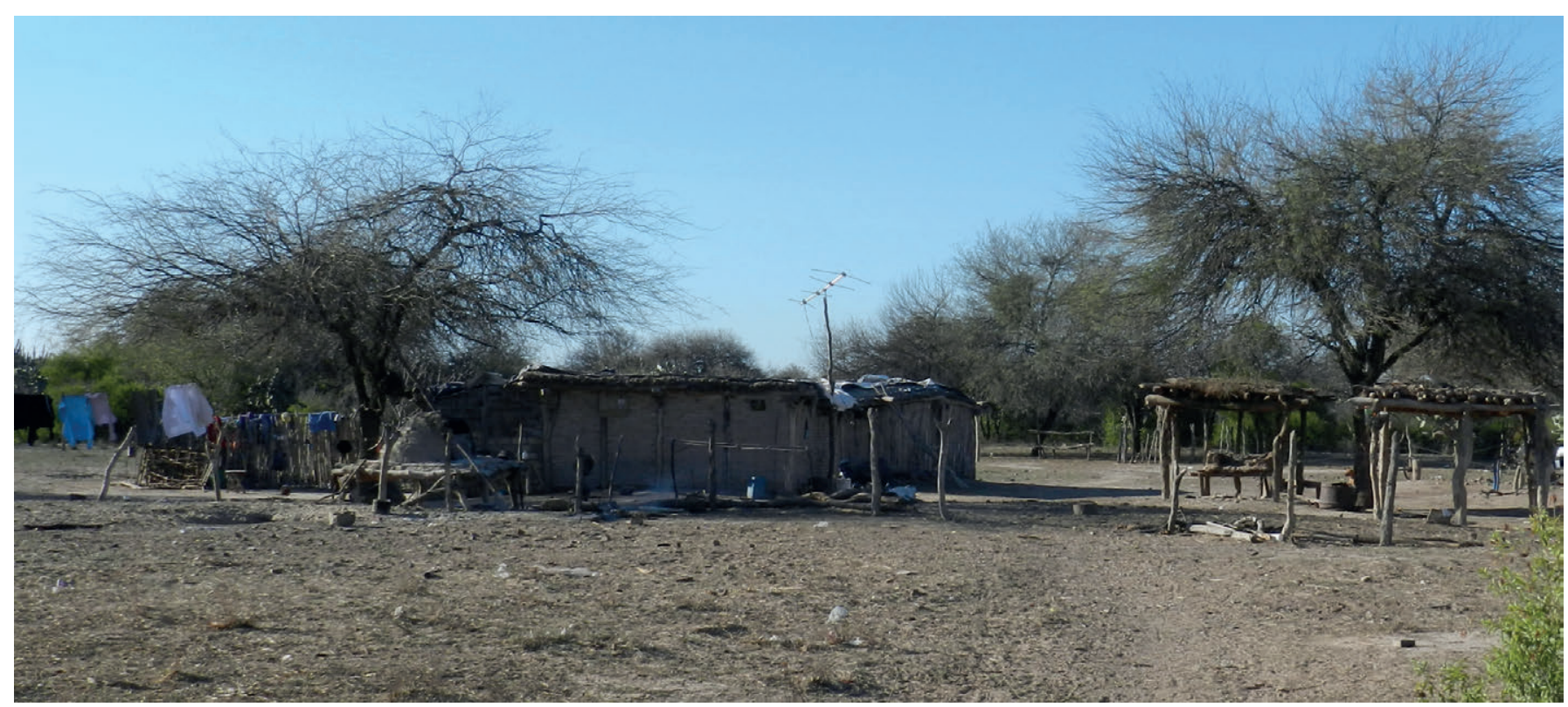

Fig. 3. Espacio doméstico y vivienda tradicional cercanos al sitio Sequía Vieja (Familia Silva). Fotografía de la autora.

-indígenas que al momento del arribo hispano ocupaban la actual zona de Córdoba y parte de la llanura santiagueña- la caracteriza efectivamente en dicho sentido, conformada por "...cuatro horcones clavados en tierra; techo asentado sobre estos palos, de ramas y paja amasada con barro, paredes de adobe crudo, grosero o de tierra pisoneada, o de quincha, tan sólo, y puerta de caña, de tientos, o de varas de alguna planta forestal" (Cabrera 1931 en Di Lullo 1943: 81).

Con base a la orientación señalada, generamos entonces expectativas arqueológicas sobre el potencial registro arqueológico que cabría esperar de haberse dado una organización del espacio, actividades cotidianas básicas y prácticas constructivas similares a las actuales (Figs. 3 y 4) y al modelo en juego, así como otras que pudieran rechazarlo parcial o totalmente. El modelo concibe un espacio doméstico prehispánico tardío organizado, pero constructivamente discontinuo, en torno a un ambiente principal techado usado fundamentalmente para el resguardo de bienes y personas, con posibilidad de estructuras menores semi-cerradas (por ejemplo, cocina) y áreas al aire libre donde se desarrollaría la mayor parte de las actividades dada la posibilidad de iluminación, ventilación, comunicación, amplitud, etc. Las ofertas y limitaciones ambientales de la región serían muy posiblemente determinantes de una tecnología constructiva mixta, basada en tierra y especies vegetales, como es la tradicional del lugar, aun cuando las formas de resolución pudieran ser diferentes e incluir otros materiales.

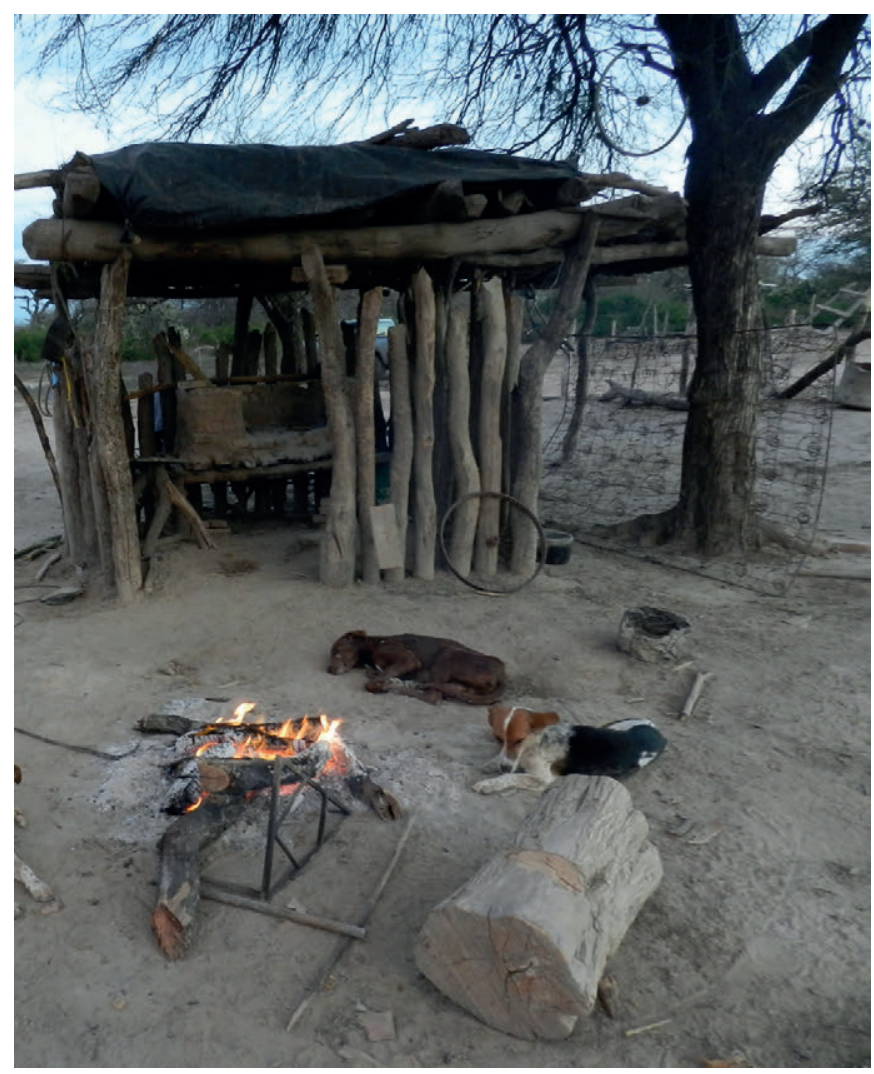

Fig. 4. Cocina tradicional semicerrada y fogón principal externo (Familia Silva). Fotografía de la autora.

También se generaron expectativas arqueológicas a partir de la observación actual de construcción, remodelación, desarme, abandono y deterioro de viviendas 
de este tipo en relación a pensar su historia de vida (Schiffer 1972; Taboada 2005). Cierra el modelo una concepción dinámica de la arquitectura (Stevanovic 1997; Taboada 2003, 2005, 2010), en tanto puede ir cambiando a medida que se transforman las necesidades de la unidad doméstica que la habita, y del proceso de deterioro de las construcciones. Esto incluye la posibilidad de modificaciones estructurales y de ubicación por acciones de remodelación y reutilización de materiales, como se da hoy a medida que el rancho santiagueño va envejeciendo. Cabe resaltar la intensa afección por lavado y salinización de estas construcciones mixtas, ante lo cual es frecuente el desarme y rearmado en espacios contiguos, con reutilización de postes de quebracho por varias generaciones, reformulación del uso de estas áreas, e inclusión de restos de las construcciones caídas (tierra de techos y muros) y rasgos (hoyos de poste, bordes del piso) a la matriz del suelo de un espacio que acoge nuevas actividades y usos, con importantes implicancias a nivel de registro arqueológico (Fig. 5).

\section{ANÁLISIS DEL REGISTRO ARQUEOLÓGICO LOCAL}

\section{Primera parte: nuevos datos de campo}

A partir de 2011 iniciamos trabajos de campo en sitios arqueológicos de la cuenca del río Salado medio-sur (en el área de los Bañados de Añatuya de Santiago del Estero) que no se trabajaban desde la década del 40 del siglo XX, concentrándonos en el estudio del sitio Sequía Vieja (ver fig.1). Varios fechados obtenidos y contextos excavados dan cuenta de una ocupación prehispánica tardía y colonial (Taboada 2014), manejando la hipótesis que Sequía Vieja fue un asentamiento indígena prehispánico que se transformó en asiento del pueblo de indios de Lasco durante la Colonia (Taboada y Farberman 2014). Los sitios de esta zona presentan - además de las evidencias de desarrollo local - bienes incaicos, que pensamos son el resultado de interacciones con el Tawantinsuyu (Angiorama y Taboada 2008; Taboada y Angiorama 2010; Taboada, Angiorama, Leiton y López Campeny 2013). Estos y otros indicadores no han llevado a plantear que, al menos, para momentos prehispánicos finales, las poblaciones de esta zona estaban lejos del estereotipo de sociedades simples con que se caracterizó a los pueblos de tierras bajas, mostrado, en cambio, capacidad de negociación política y caciques sostenidos durante la Colonia (Taboada y Farberman 2014; Taboada 2016).

El área de los Bañados de Añatuya se inserta en plena llanura en el chaco santiagueño, a una altura media de 90 m.s.n.m. Presenta vegetación de monte xerófilo y gran dinámica fluvial. Es periódicamente afectada por desbordes estivales del río Salado y por sequías en época invernal. El sitio Sequía Vieja ocupa un área naturalmente algo más elevada que el área circundante. Se extiende por 15 ha y se compone de decenas de montículos de diverso tamaño y altura que no siempre presentan solución de continuidad, formando terraplenes. La densidad vegetal y la ausencia de material rocoso dificultan aproximaciones a su estructura y función sin intervenciones. Los montículos y terraplenes se

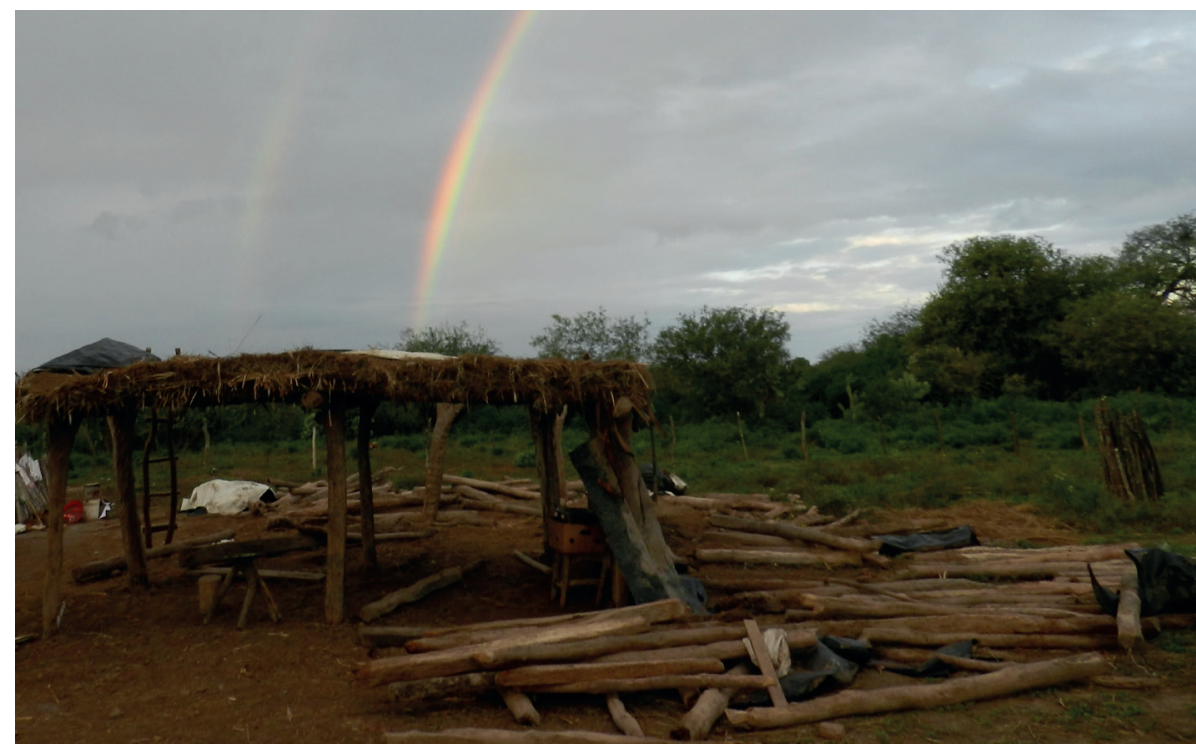

Fig. 5. Reutilización de espacio y materiales. Nueva habitación en proceso de construcción a partir del reuso de troncos procedentes del desarme de la estructura de palo a pique ilustrada en la figura 2 que ocupaba el área inmediata contigua (Familia Silva). Fotografía de la autora. 
combinan con relieves negativos longitudinales y pseudocirculares. Si bien, en general, coinciden con paleocauces, no se descarta su potencial acomodamiento y uso antrópico (Ortiz y Fernández 2014) como represas y canalizaciones para deriva de agua que ya señalaran los Wagner (1934) y algunas fuentes coloniales (Lorandi 2015). Entre medio $\mathrm{y}$ en los bordes quedan áreas planas, que podrían haber funcionado como espacios públicos, áreas de cultivo, etc.
En este marco, los principales aportes para el estudio del espacio doméstico fueron las excavaciones que practicamos en los sectores SV150 y SV157 del sitio (Figs. 6 y 7). Corresponden a sendos montículos y sus áreas bajas inmediatas, distantes entre sí $350 \mathrm{~m}$ en línea recta, y mediados por alta densidad de evidencias arqueológicas muebles y formaciones monticulares. A continuación presentamos su análisis.
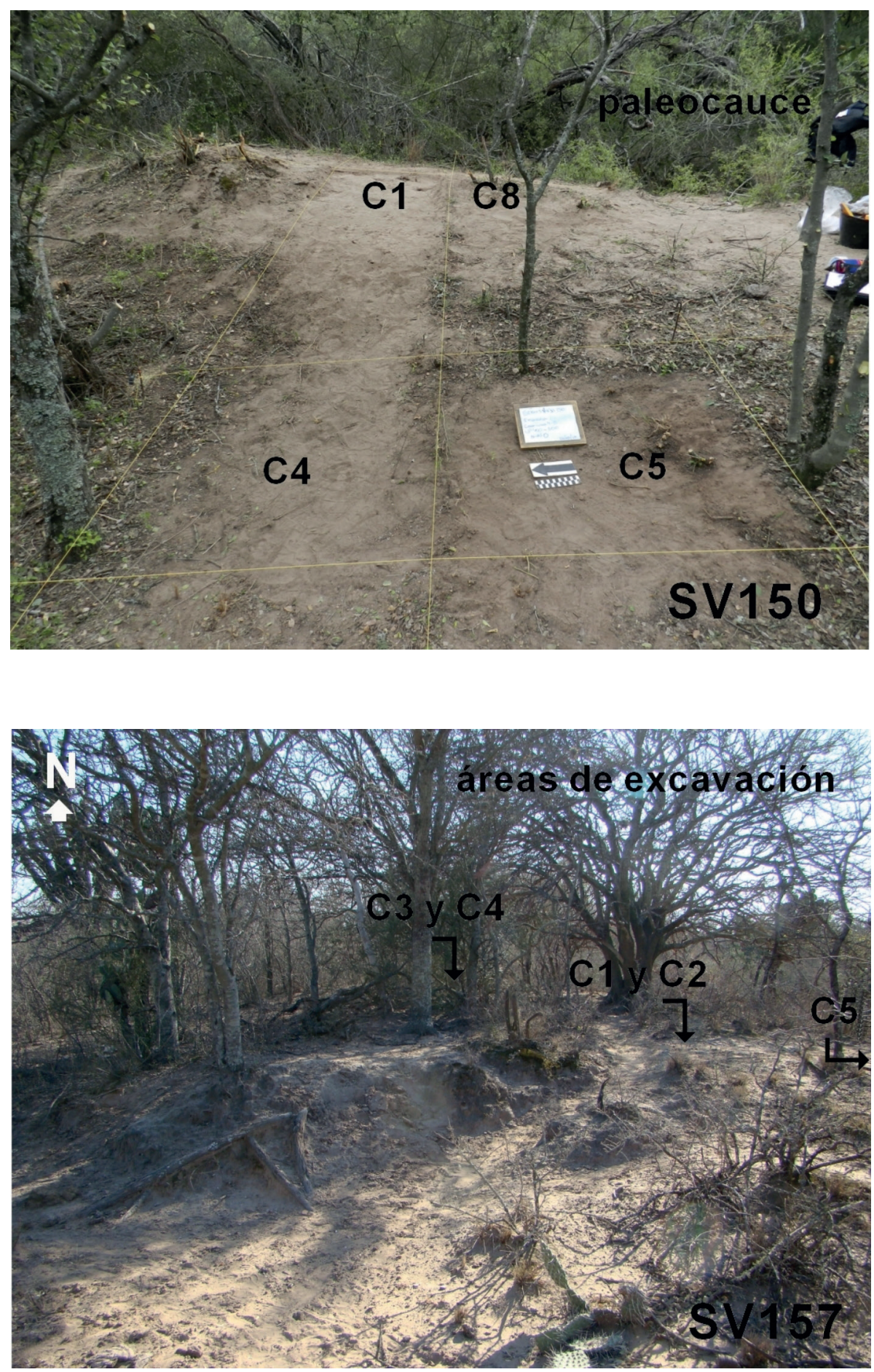

Fig. 6. Foto del Montículo SV150 con indicación de las cuadrículas excavadas 1 , 4,5 y 8 . Las demás cuadriculas excavadas no se aprecian en la foto por ubicarse en la cima del montículo. Ver fig. 8. Fotografía de la autora.
Fig. 7. Foto del montículo SV157 con ubicación de las cuadrículas $1,2,34$ y 5 excavadas. Fotografía de la autora. 


\section{Caso 1: Montículo SV150}

\section{Descripción y análisis de SV150:}

Montículo de planta aproximadamente oval y perfil abombado. Por su lado oeste presenta un talud bien marcado y por el sudeste colinda con una hondonada pseudocircular de aproximadamente las mismas dimensiones que el montículo, inserta a su vez en un aparente paleocauce ${ }^{2}$. Hacia los otros lados, se diluye en una elevación de tierra compuesta por una sucesión de montículos sin límites precisos a lo largo del paleocauce referido. Presenta una altura máxima conservada sobre el nivel general actual de $0,90 \mathrm{~m}$.

El contexto tiene un fechado radiocarbónico entre prehispánico tardío y colonial temprano: $460 \pm 50$ años AP (calibrado con $1 \sigma: 1432-1500$ AD (p. 0,881682) y 1597$1611 \mathrm{AD}$ (p. 0,118318)). La muestra datada se hallaba incluida en una matriz que se interpretó como el piso de una vivienda (según veremos más adelante). Se estimó que podría corresponder y datar el momento de arreglo del espacio de ocupación. Sin embargo, si bien la muestra presenta una mayor probabilidad de ser prehispánica, el fechado puede estar envejecido si el piso contenía carbón de maderos con usos anteriores ${ }^{3}$. El material cerámico decorado corresponde al estilo prehispánico tardío Averías ${ }^{4}$, pero que continuó en uso en tiempos de la Colonia temprana. Por su parte, el hallazgo de algunos pocos elementos de

2 Un estudio geomorfológico específico llevado adelante por Guillermo Ortiz apunta actualmente a determinar si puede corresponder a un canal antropizado.

3 Actualmente los postes de las viviendas se recuperan y reutilizan hasta por lo menos tres generaciones, terminado en el fogón cuando se descartan. 4 Ver más adelante ilustración en Fig. 13. origen hispano (un fragmento de loza Talavera y otro de loza blanca, un fragmento de hierro, dos cuentas coloniales de vidrio) tampoco es determinante de esta cronología de uso, ya que se recuperaron en depósitos de relleno y el asentamiento llegó a momentos coloniales.

El montículo fue excavado abriendo en área dos sectores, uno en la cima, de $5 \mathrm{~m}^{2}$, y otro en la base, de $2 \mathrm{~m}^{2}$, más un perfil practicado en el límite con el paleocauce (Fig. 8). Las excavaciones pusieron en evidencia una estratigrafía bien diferenciada por sectores, según detallamos a continuación (Figs. 9 y 10).

\section{Estratigrafia del sector superior de SV150}

A. NUCLEO: Masa limosa blanquecina sin material cultural, de forma abovedada por sobre el nivel del terreno. Se interpretó como el núcleo (natural o preparado ${ }^{5}$ del montículo, asiento de un piso y construcción habitacional.

B. PISO: Capa compacta de sedimento similar al del núcleo (A), dispuesta a modo de plataforma sobre él. Presenta superficie horizontal, mostrándose rebajado el borde expuesto. No se detectaron concentraciones de restos, fogones ni rasgos que pudieran adscribirse $\mathrm{a}$ áreas de actividad. Un pozo de $0,20 \mathrm{~m}$ de diámetro

\footnotetext{
5 Observaciones realizadas en un perfil (cuadrícula 12) que colinda con el área negativa y paleocauce parecen indicar la posterioridad de formación del montículo respecto de éstos y una estructura de base del mismo de origen no fluvial (M. Collantes, com. personal), eventualmente construida. El tamaño de la hondonada colindante podría indicar el área de extracción de tierra. Sin embargo, se requiere aún profundizar estudios para determinar si el núcleo de base es natural o no y si la hoyada pudo cumplir alguna función de reserva de agua.
}

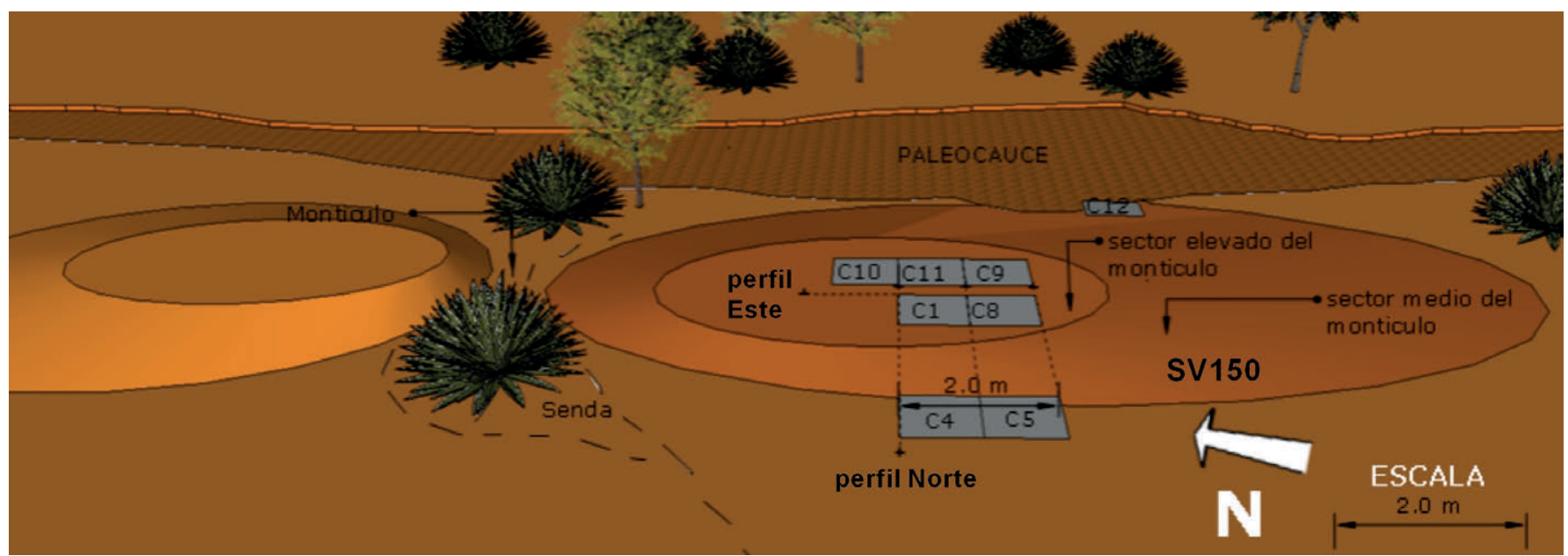

Fig. 8. Croquis de SV150, con indicación de las cuadrículas excavadas. Realizado por Guillermo Ortiz. 


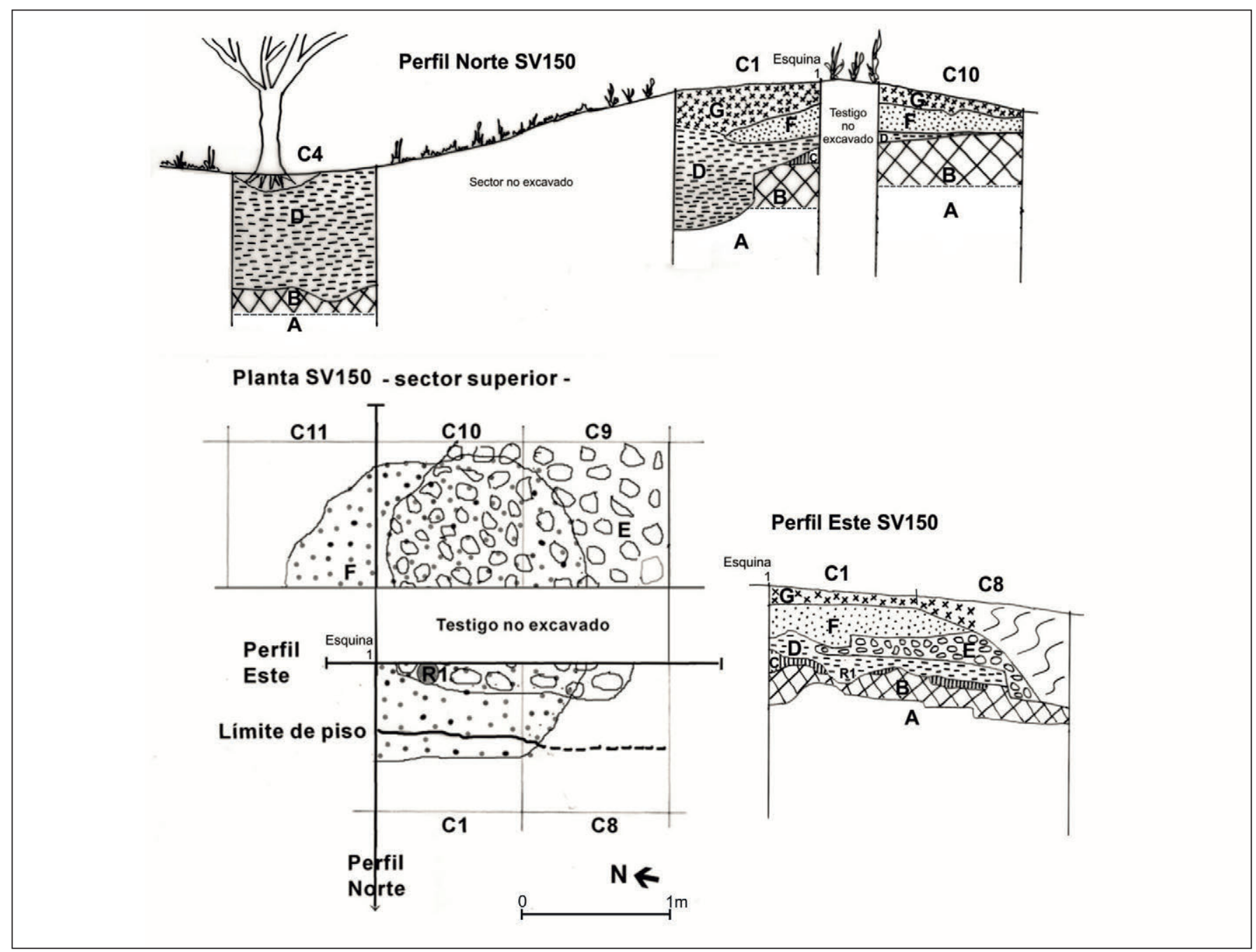

Fig. 9. SV150. Perfil Norte de las cuadrículas 1 y 4. Perfil Este de las cuadrículas 1 y 8 . Planta del sector superior con áreas que cubren el techo, límite del piso, lente de arena y ubicación del Rasgo 1. Las letras de referencia de cada estrato/nivel remiten a la descripción que se presenta en el texto. Gráficos realizados por la autora y digitalizados por Gustavo Carello.

con una huella carbonosa de $0,10 \mathrm{~m}$ de diámetro en su interior (Rasgo 1-R1) se ubicó coincidiendo con el límite lateral tanto del piso consolidado como del estrato de techo (E). La matriz del nivel presentó abundante fósforo, espículas de carbón y escaso material cultural (fragmentos cerámicos, huesos de fauna, y varios torteros especialmente en la cuadrícula $^{6} 11$, fuera del área con techo). Se concluyó que el nivel se correspondía a un piso de vivienda con material incluido por pisoteo y/o en la preparación misma. El Rasgo 1 (R1) se interpretó como un pozo y huella de poste vinculado al techado. El rebajado en el límite del piso podría remitir a la zanja para

\footnotetext{
6 En más, las cuadrículas se referirán mediante una $\mathrm{C}$ seguida del número correspondiente: C11.
}

calzar muros de estructura vegetal (y/o recuperar troncos) que se practica en las construcciones tradicionales.

C. RESTOS DE ESTRUCTURA (?) VEGETAL: Estrato discontinuo blanco jaspeado (materia orgánica descompuesta (?)) asociado a restos de cañas y ramas parcialmente incluidos en la compactación del piso. Podría corresponder a restos de paramentos tipo quincha.

D. DEPOSITO POR MUROS MIXTOS CAIDOS (?): Depósito suelto, oscuro, de estructura granulosa y con terrones. Mostró escaso y fragmentario material arqueológico, en principio, no remontable ni roto in situ. Presentaba gran potencia en el talud (perfil Norte, C1), escasa entre el piso y el techo (perfil Este, C8), y mínima sobre el sector de piso que no cuenta con registro de techo (perfil Norte, C10). 


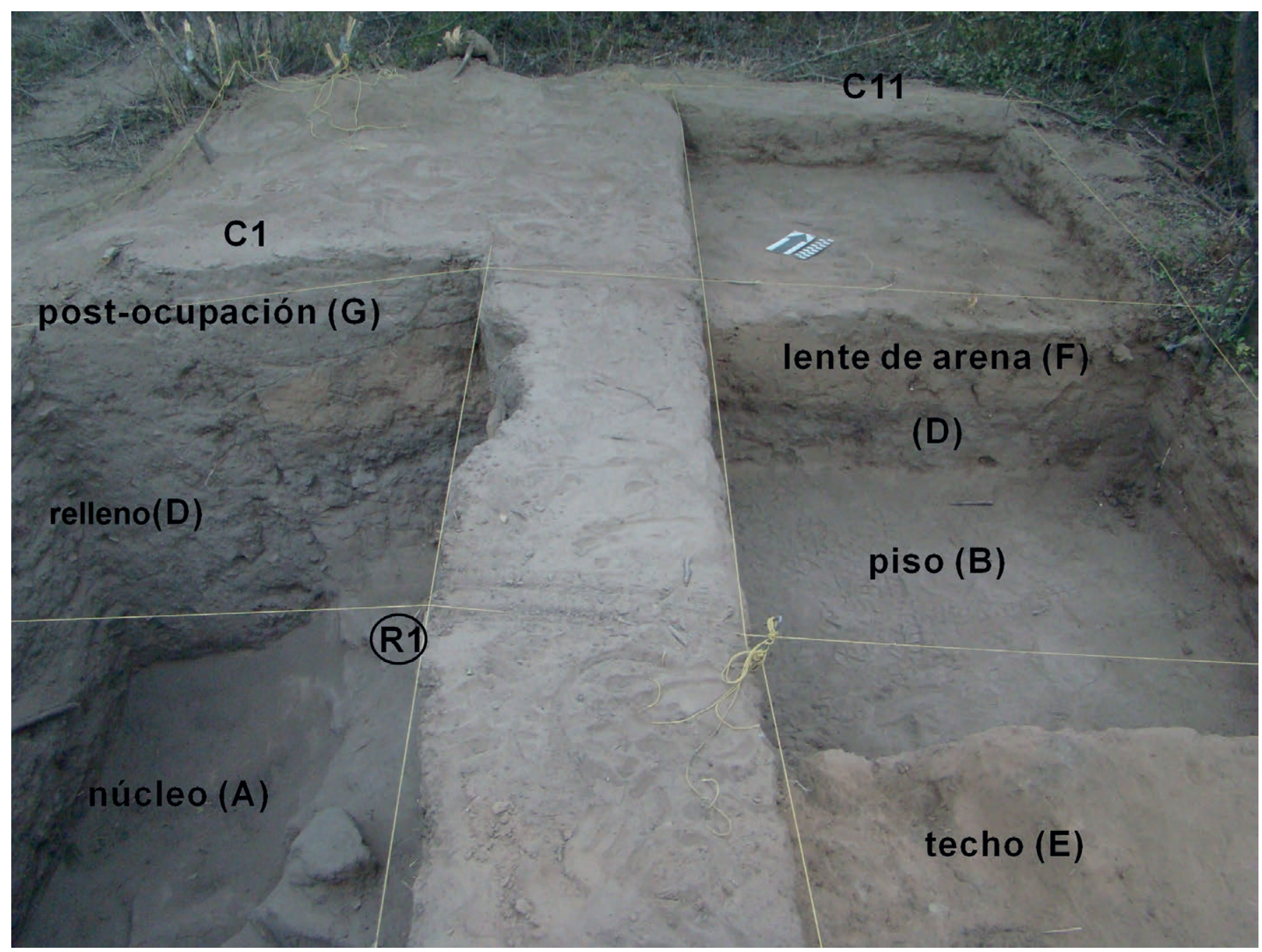

Fig. 10. Foto de excavación de SV150 con referencia a estratos. Fotografía de la autora.

Es un depósito formado antes de la caída del techo (E). Parece ser una matriz de origen vegetal y tierra. Podría corresponder a muros mixtos colapsados mezclados con elementos culturales asociados al espacio habitacional.

E. TECHO: Capa horizontal (0,15-0,25 m de espesor) compuesta por material orgánico oscuro recubierto por tierra arcillosa rosada. Coincidía con parte de la planta del piso expuesto (el piso es de mayor dimensión), con el límite rebajado del mismo y con la huella de poste (R1). Se interpretó como un techo caído formado por vegetales y una capa de arcilla (análogo a las cubiertas tradicionales), y constituye el primer registro de un techo arqueológico para Santiago del Estero. Habría colapsado sobre el derrumbe de muros (D), implicando la caída previa de los mismos. Esto es posible si los muros no son portantes, como se da en las construcciones actuales.
F. LENTE DE ARENA: Depósito acotado de arena, sin material cultural. Se extendía cubriendo parcialmente los depósitos de relleno (D) y techo (E). Si bien podría ser natural ${ }^{7}$, por lo acotado se especula con un aporte intencional de arena sobre los restos de la vivienda caída, quizás para cubrirlos o acondicionar el espacio para otros usos (ver $G)^{8}$.

G. DEPOSITO POSTOCUPACION HABITACIONAL: Estrato superior con bastante material cultural. La dificultad para explicar la "subida" del material por factores naturales ${ }^{9}$ permite pensar en el desarrollo de actividades,

Si bien depósitos de arena podrían ser dejados por desborde de ríos -hay un paleocauce inmediato-, este lente tan acotado, y dispuesto sólo en la parte más alta del montículo, no parece poder interpretarse por este efecto (no se registró sedimentación similar en sectores aledaños).

8 Actualmente se realiza esta operación a fin de que las taperas derruidas no junten basura.

9 Salvo una inundación y arrastre que cubra la altura del montículo, de lo que no hay evidencia. 
tránsito o eliminación intencional de elementos sobre él. Podría corresponder a un nuevo uso del espacio - menos formalizado- luego de caída la construcción.

\section{Estratigrafía del sector inferior de SV150 (ver fig. 9)}

A. NIVEL DE BASE: Matriz compacta limosa blanquecina que parece conformar el mismo depósito que el estrato (A) de la cima. Estéril arqueológicamente. Se interpretó como la base sobre la que se produjo la ocupación y uso del espacio.

B. PISO/NIVEL DE OCUPACION: Depósito horizontal compacto y rojizo. Contenía poco material, en general fragmentos grandes (algunos de la misma pieza) dispuestos horizontalmente a lo ancho de pocos centímetros. Presentaba una superficie irregular y varias concavidades de poca profundidad con restos oscuros o carbonosos, sin evidencia de acción del fuego ${ }^{10}$. Se interpretó como el nivel de uso de un área de circulación, descarte y/o actividades no necesariamente recurrentes vinculadas a la vivienda ubicada en la cima.

C. RELLENO. Depósito oscuro muy potente, sin diferencias sedimentológicas ni estratigráficas relevantes. Parece constituir una unidad estratigráfica con el depósito (D) de la zona cumbral. Contenía material cultural sin orden evidente: fragmentos cerámicos, huesos de fauna y algunos pocos objetos pequeños. También se registraron concreciones asignables a partes de muros y techo. La matriz se disponía en "cuñas" paralelas a la pendiente, lo que permite pensar en un aporte de material desde arriba en un evento rápido (P. Cuenya, com. personal). Este depósito fue interpretado como producto de la acumulación por caída rápida de materiales desde la parte superior, posiblemente por derrumbe de la vivienda ${ }^{11}$.

No se detectó un nivel estratigráfico que pudiera corresponderse con el depósito G de la cima. No obstante, la densidad de material es menor en el sector superior y podría caber una diferenciación con base a ello.

\section{Interpretación de SV150:}

$\mathrm{El}$ análisis estratigráfico permite proponer que el sector excavado en la cima formaba parte de un espacio de uso

\footnotetext{
${ }^{10}$ Nos preguntamos si estas concavidades podrían ser huellas de empalizadas que contuvieran el perímetro del montículo. Esta práctica ha sido registrada en las tierras bajas sudamericanas.

11 Por el momento se da prevalencia a esta hipótesis por sobre la de aportes paulatinos por descarte, ya que además de lo dicho, el depósito no evidenció estructura de basurero (por ejemplo, laminaciones, o agregados de materiales que parecieran arrojados juntos).
}

doméstico. Parte habría estado techado con torta de vegetales y arcilla y posiblemente estuviera cerrado lateralmente con muros mixtos. Sería asignable a un ámbito interior de vivienda usado para el resguardo de personas y bienes, sin evidencias de otras actividades a su interior (por ejemplo, culinarias o de manufactura). Por su parte, mientras el piso continúa hacia el norte con un mayor registro de material de facto (principalmente torteros ${ }^{12}$ ), no lo hace el techo (E) ni los restos asignables a vegetales (C) (ver figs. 9 y 10). Esto lleva a pensar que dicho sector pudo no estar techado ni cerrado, constituyendo un área extramuros. La ausencia de registro de muros, el rebajado del piso en su límite externo y el potente depósito D lleva a plantear el derrumbe de la estructura y la posibilidad (a seguir indagando) de recuperación de materiales constructivos. El lente de arena y la situación de los depósitos superiores hacen factible pensar en una reutilización del espacio.

Las características identificadas permiten entablar una identidad muy cercana con datos arqueológicos aportados para la región por von Hauenschild (1949, s.a.), Reichlen (1940) y Greslebin (1934) sobre pisos consolidados, bien definidos en forma y espesor a modo de plataformas, que a la luz de nuestras excavaciones retroalimentan su comprensión y que analizaremos en la segunda parte del artículo.

\section{Caso 2: Montículo SV157}

\section{Descripción y análisis de SV157:}

Montículo de perímetro bastante definido y mayores dimensiones que el de SV150, con una altura máxima conservada de $1,16 \mathrm{~m}$. Se lo intervino en la zona cumbral $\left(2 \mathrm{~m}^{2}\right)$, media $\left(2 \mathrm{~m}^{2}\right)$ y base $\left(1 \mathrm{~m}^{2}\right)$ (Fig. 11). Los sectores excavados presentaron una sucesión de eventos estratigráficos de difícil definición, acrecentada por la escasa superficie expuesta. Un único elemento de cronología colonial (un fragmento de cerámica vidriada) hace necesario plantearse esta temporalidad de uso, aunque con dudas por proceder de zaranda y estar el depósito alterado. No tenemos fechados. El material cerámico decorado corresponde al estilo Averías. Se estima una cronología similar a la de SV150, entre prehispánico final y colonial. Dado que los perfiles y planta no son representativos, presentamos a continuación una lectura general de la situación.

\footnotetext{
12 Cabe señalar que la actividad de hilado se realizaba, al menos en la Colonia temprana, tanto en el ámbito doméstico como al aire libre en espacios compartidos.
} 


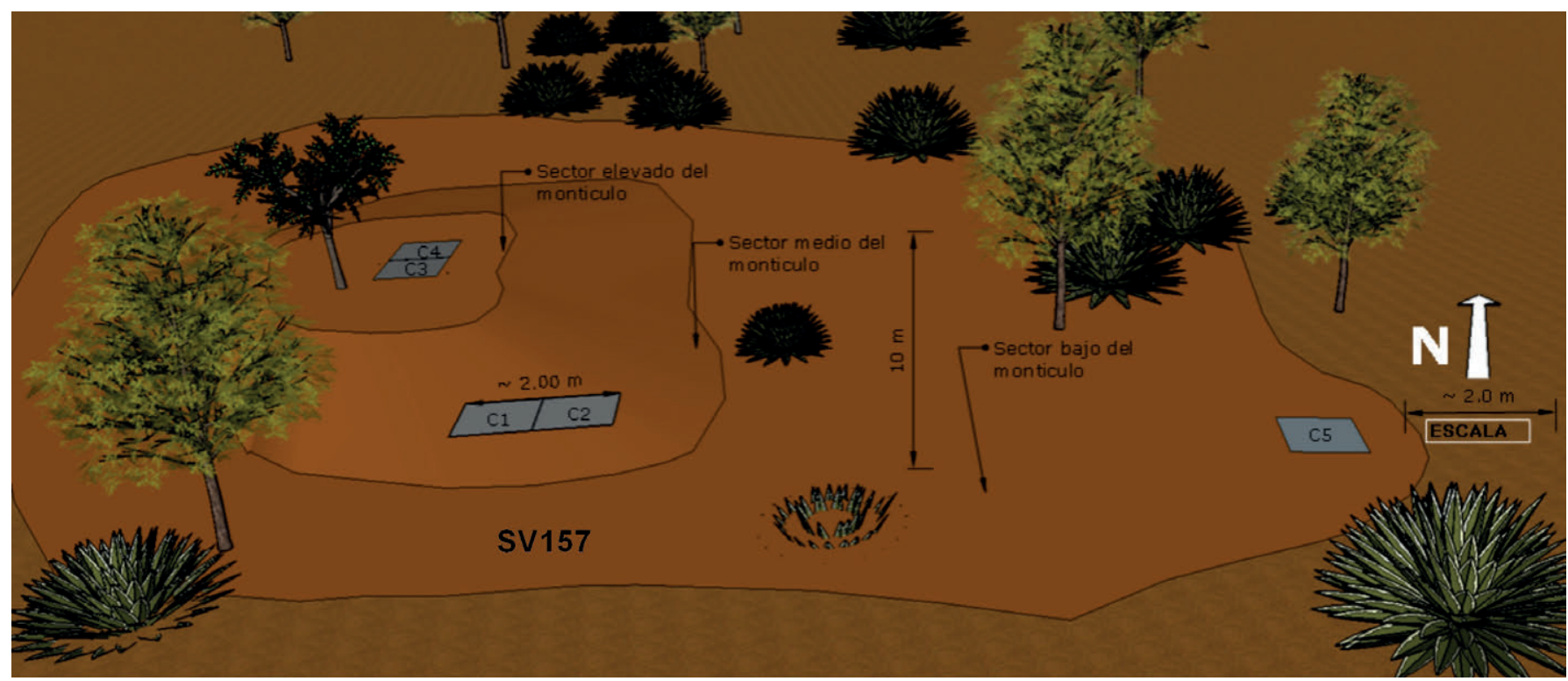

Fig. 11. Croquis de SV157, con indicación de las cuadrículas excavadas. Realizado por Guillermo Ortiz.

En la excavación de un área lateral de la cima (C3 y C4), el depósito más profundo se componía de una matriz compacta, blanquecina, de textura fina, arqueológicamente estéril, similar a la del núcleo de SV150. Por encima, se determinó una capa horizontal compacta y blancuzca que parece constituir un piso o nivel de uso. Hacia el interior del montículo formaba un pozo con carbón y ceniza. Este podría tratarse de un rasgo vinculado a cocción de alimentos, ya que el piso adyacente presentó grandes fragmentos de platos y ollas, carbón y huesos de fauna quemados. Este contexto aparecía cubierto por sedimento suelto, a modo de relleno. Arriba de él se disponía una capa no muy definida de cañas, que quizás pudieron constituir una mampara o techo liviano similar a los que actualmente se hacen en cocinas y espacios semicerrados ${ }^{13}$. Los estratos superiores no mostraron una definición clara como para avanzar en interpretaciones hasta ampliar las excavaciones, pero parecen corresponder a depósitos de relleno y caída de materiales.

La excavación en el área media del montículo $(\mathrm{C} 1$ y C2) mostró un depósito diferenciado al de la cima, compuesto por abundante material ecofactual en concentraciones horizontales y capas discontinuas, pero sin estratos estériles. El nivel de base estaba constituido por una matriz limosa compacta, rojiza y estéril. Por encima, una matriz similar con material cultural parecía constituir un primer nivel de uso. La misma estaba cortada por un pozo de $30 \mathrm{~cm}$ de profundidad y $70 \mathrm{~cm}$ de

\footnotetext{
13 Alternativamente nos preguntamos si las cañas no podrían corresponder a una cobertura similar a la que Lorandi (2015) registra sobre los hornos del sitio El Veinte, aunque el rasgo no muestra otras similitudes morfológicas.
}

diámetro, donde se recuperaron fragmentos cerámicos y algunas semillas. A partir de allí, y hasta la superficie, se disponía un potente depósito compuesto por restos de fauna, carbón, ceniza, nódulos de barro calcinados, pocos fragmentos cerámicos, algunos quemados, arena carbonosa y diferentes aportes sedimentarios, material que en conjunto parece constituir limpiezas de fogones y descarte de comida, pero no áreas de actividad in situ.

Un sondeo en el sector bajo del montículo (C5) mostró un depósito muy poco fértil. Como nivel de base presentó una matriz clara, compacta y estéril que pudo ser comprobada hasta los 2,36 $\mathrm{m}$ de profundidad por medio de una prueba de barreno y que, al igual que SV150, muestra la aparente ausencia de albardones naturales de arena como base de este montículo, pero que requerirá de mayores estudios para su ratificación. Sobre este nivel se disponía un depósito con sectores muy compactos y sedimento suelto con escasísimo material (cerámico y óseo); por encima, un depósito blancuzco con muy escaso material y carbón disperso.

\section{Interpretación de SV157:}

El contexto excavado en la parte superior parece constituir un nivel de ocupación asociado a actividades de uso del fuego y elaboración y consumo de alimentos. La evidencia es compatible con un área semicerrada por un techado y/o tabique de cañas ${ }^{14}$. El piso coincide con el

\footnotetext{
14 Resulta interesante tener presente que los espacios de preparación y uso del fuego y cocina tradicionales de la región se desarrollan fuera del espacio principal cerrado por la combustibilidad de los materiales constructivos (ver fig. 4).
} 
nivel consolidado detectado en el sector medio del montículo y correspondería al primer uso de dicho espacio. El sector medio parece haber servido, posteriormente, como área de descarte de restos de alimentación. La cercanía al área propuesta como de preparación de alimentos apoya la interpretación funcional del espacio en su conjunto. La situación permite entablar ciertos paralelos — dado además su similar contexto cronológico cultural - con la descripción de una posible "cocina" referida por von Hauenschild (s.a.) que analizaremos en la segunda parte del artículo. El sondeo en el sector inferior daría cuenta de un área marginal a los espacios de actividad recurrente.

\section{Segunda Parte: relectura de las situaciones de la bibliografía}

Analizamos ahora los datos recuperados de la bibliografía en función de nuestras preguntas y de los contextos analizados anteriormente. Dado que la mayoría de la bibliografía que aporta al tema (salvo los trabajos de Lorandi) se generó dentro una arqueología pre-científica, la asignación cronológica, funcional y el marco sociocultural propuesto son producto de un re-análisis de la documentación a la luz de los modos y condiciones de producción de cada autor (Martínez, Taboada y Auat 2008, 2011), razón por la cual se expone en detalle el proceso interpretativo que hemos realizado. De nuestra lectura hemos diferenciado 3 Situaciones (A, B y C) o tipos de montículos, que exponemos a continuación.

\section{Situación A}

Contamos con 4 casos que asignamos a esta situación en base a reconocer una recurrencia de caracteres morfológicos, estructurales y de composición de pisos bien delimitados (Fig. 12), asimilables a la situación de SV150. Ellos son:

\section{Caso A.1. Montículo del sitio Cayo López (Reichlen 1940)}

- Ubicación: Sitio del chaco santiagueño, al noreste del río Salado (ver fig. 1).

- Cronología y asociación cultural: El sitio presenta cerámica Averías y ausencia de alfarería Sunchituyoj y de material colonial (Fig. 13). Se estima una cronología prehispánica tardía. Según Reichlen es un importante sitio de montículos, de los cuales excava uno completamente. Indica su carácter habitacional y similitud con los de la zona de los Bañados de Añatuya.
- Registro e interpretación: El montículo presentaba un núcleo oval, según Reichlen artificial, de tierra tomada del terreno circundante. Tenía $15 \times 13,5 \mathrm{~m}$ en la base. Presentaba en la parte superior una capa rectangular compacta (de 0,20-0,25 m de espesor y 5 x $5,5 \mathrm{~m}$ de superficie) de la misma composición que el núcleo, análoga a la de SV150 y a las que veremos refieren von Hauenschild y Greslebin. Bajo este piso halló una escudilla, situación que se repite también en los otros casos que analizaremos. Por encima del piso y también del núcleo en los sectores laterales, Reichlen halló un depósito conformado por ceniza, espinas de pescado, huesos de fauna, puntas de piedra, cuentas de caracol, figurinas cerámicas y unos 2.000 fragmentos. También encontró fragmentos de 18 "campanas" (sensu Serrano 1938) en asociación con conos de cerámica, que asimila con los soportes para ollas de la zona de Mojos en Bolivia referidos por Nordenskiöld. La indiferenciación por parte del autor de este depósito superior no permite más que especulaciones. Pensando en el caso de SV150, podría estar aunando materiales de actividad culinaria sobre el nivel de uso, de descarte y derrumbe de la vivienda en los bordes del montículo, e incluso de una postocupación. En las partes bajas del montículo, Reichlen halló 4 urnas con restos humanos.

\section{Caso A.2 .Montículo de Colonia Chilca (Greslebin1934)}

- Ubicación: El paraje Colonia Chilca está ubicado en el área del río Dulce (ver fig. 1). Según Argañaraz (en Greslebin 1934) el sitio corresponde al de Huilla Catina.

- Cronología y asociación cultural: El sitio registra alfarería Negro sobre Rojo Brillante, una vasija con representación de búho en Negro sobre Rojo que Lorandi estima de la fase Quimili Paso ${ }^{15}$, y material Averías, entre el cual hay un puco con representación de búho geometrizado asignable a fase Oloma Bajada-Icaño (Lorandi 1978). No se conocen evidencias coloniales. Se calcula una cronología prehispánica tardía para el sitio en general.

- Registro e interpretación: Montículo ovoide de 21,40 y $16,40 \mathrm{~m}$ y altura máxima de $1,53 \mathrm{~m}$; fue excavado sólo parcialmente. Según Greslebin, tenía como base

\footnotetext{
${ }^{15}$ Las tres fases propuestas por Lorandi (1978) para la Tradición Chaco Santiagueña y las cronologías originalmente asignadas son: Las Lomas (1000-1200 d. de C.), Quimili Paso (1200-1350/1400 d. de C.) y Oloma Bajada-Icaño (1350-1600 d. de C.). La calibración actual de los fechados permite hoy ampliar y superponer parcialmente estos rangos.
} 


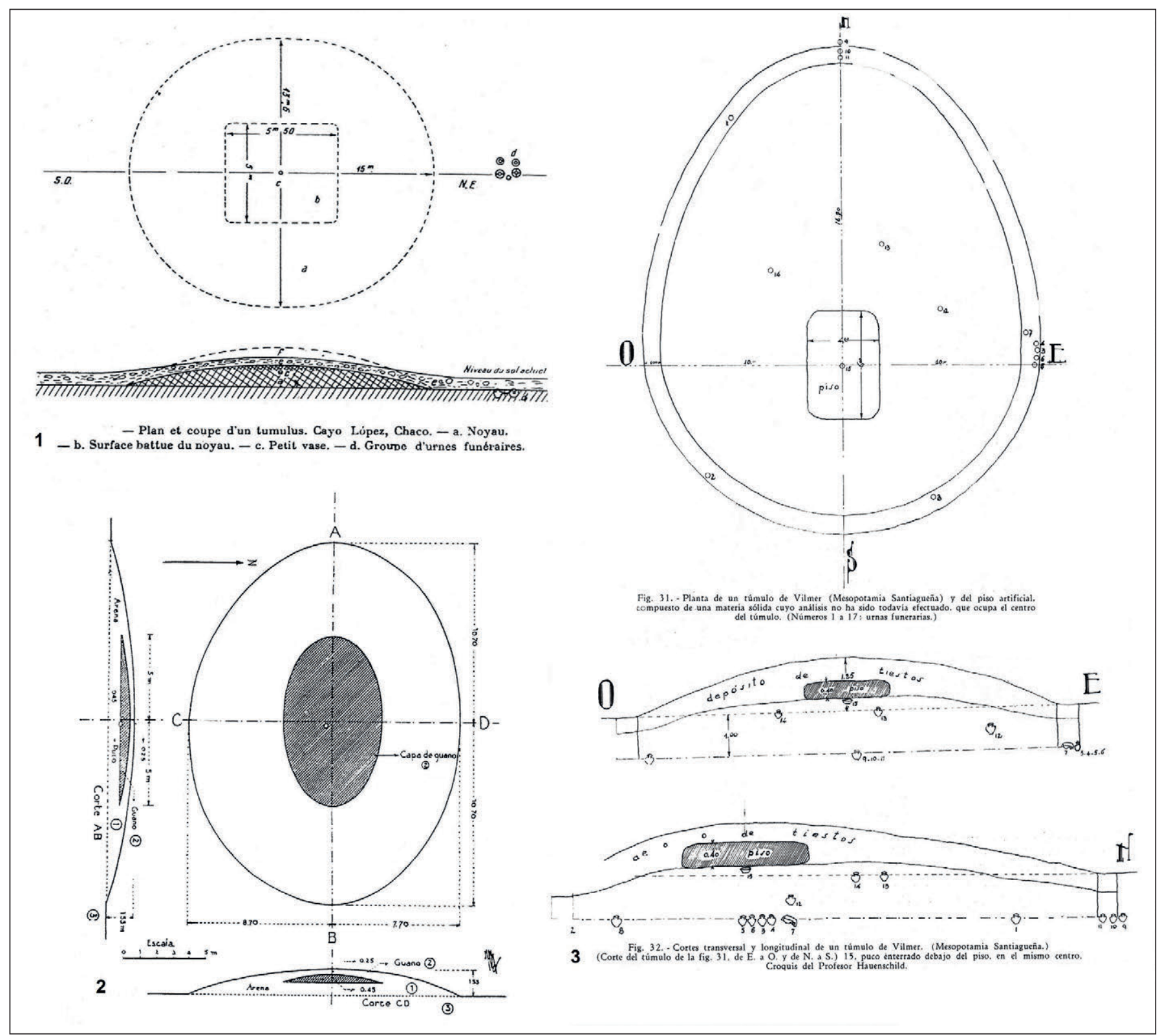

Fig. 12. Montículos de la Situación A. 1) Caso A.1. Cayo López (Reichlen 1940), 2) Caso A.2. Colonia Chilca (Greslebin 1934 ), 3 ) Caso A.3. T57 de Vilmer Norte (Von Hauenschild en Wagner y Wagner 1934). Digitalizado por Gustavo Carello.

un médano de arena y por encima una capa endurecida de planta oval y sección lenticular (de $10 \times 6$ m y $0,45 \mathrm{~m}$ de espesor máximo). El gráfico recuerda a la situación de Cayo López, a la de SV150 y a la que veremos del montículo T57 de Vilmer Norte. Sin embargo, Greslebin considera que se trata de una capa de guano ${ }^{16}$. Se señala la presencia de un "micelio blanco", comparable quizás al que referimos para SV150,

\footnotetext{
16 Los análisis realizados no pudieron comprobarlo, mostrando solamente que contenía alta proporción de materia orgánica y fosfato cálcico (Ducloux, en Greslebin 1934).
}

por lo que nos preguntamos si no estamos, más bien, ante restos de muros o techo de origen vegetal sobre un piso. La sección lenticular consolidada podría tener también su análogo en SV150, donde el piso se presenta plano en su sector medio pero rebajado hacia el borde. Hay evidencias domésticas: fogones, restos de cocina y de fauna, cerámica y algunos instrumentos de hueso y de piedra, además de la referencia a que la capa endurecida presentaba "fajas" de cenizas dispuestas irregularmente en el perfil. Argañaraz (en Greslebin 1934) propone, en base a observaciones en 

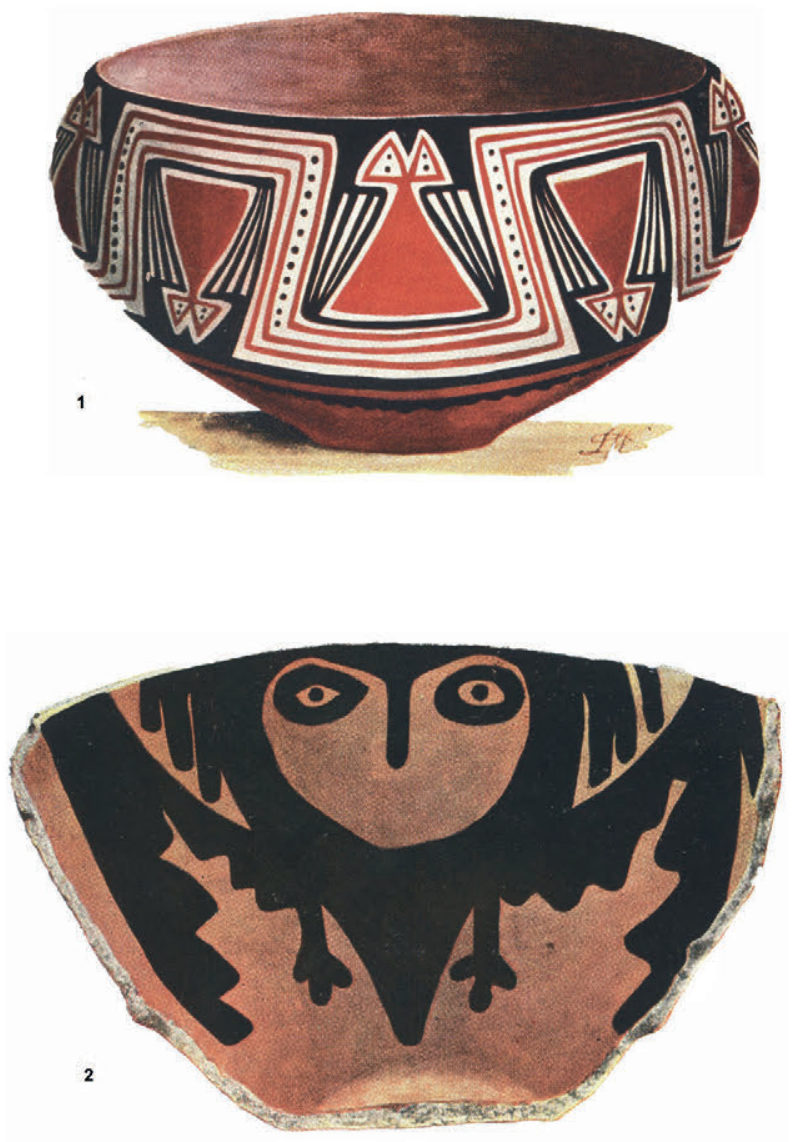

- Ubicación: Sitio ubicado en el área del río Dulce (ver fig. 1).

- Cronología y asociación cultural: Para el sitio se describe material que interpretamos como Averías, Negro sobre Rojo Brillante, y Sunchituyoj geométrico Negro sobre Rojo. El asentamiento pudo continuar en época colonial. Del T57 se describen 3 vasijas con grecas formadas por eses acostadas que podrían corresponder al material ilustrado por los Wagner (1934: Lam XLVI) y ser análogo al asignado a la Fase Quimili Paso (Lorandi 1978). Se estima cronología a partir de la fase Quimili Paso y posterior.

- Registro e interpretación: Montículo de 24 x 19,82 $\mathrm{m}$. Presentó un estrato horizontal muy duro que el autor considera un "piso artificial". Estaba delimitado por un escalón —que asimilamos al registro de SV150 - que configura una especie de plataforma con una superficie de $6 \times 4 \mathrm{~m}$ y una potencia de $0,40 \mathrm{~m}$. Bajo el piso se encontró la parte inferior de una urna con huesos. Sobre el piso se halló muy poco material, cubierto por una capa arenosa de $0,20 \mathrm{~m}$, que repite las situaciones de los otros casos analizados. El núcleo estaba formado por sedimento estéril, pero contenía 14 vasijas (la mayoría funerarias) y 5 entierros directos. La capa superior del montículo, que el autor atribuye al manto eólico - pero que nos interpela sobre su factibilidad de acumulación en la parte superior en base a lo desarrollado para SV150-, presentó abundancia de cerámica fina, figurinas y ausencia de otro tipo de materiales. Esta situación, sumada a la gran cantidad de entierros, lleva a von Hauenschild a proponer que el montículo estaba destinado exclusivamente a sepultura y culto funerario. Nosotros estimamos que tal situación no obsta para pensar un uso habitacional

similar a los demás casos. Por el contario, aporta un

arena superior que considera agregada y, sobre todo,
en los bordes del montículo, lo cual no hace más que plantearnos la posibilidad de un piso habitacional limpio de evidencias y con acumulación de materiales

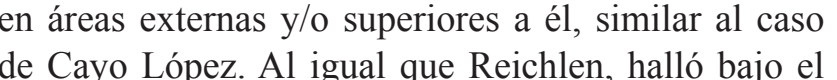
piso una escudilla, en este caso con material "similar a ceniza". En el núcleo de base se hallaron urnas con
adultos y niños, ofreciendo dos elementos más de unidad funcional con la situación referida por Reichlen y que veremos también para Vilmer Norte.

\section{Caso A.3. Túmulo 57 (T57) del sitio Vilmer Norte (Von Hauenschild 1949, s.a.)}

Fig. 13. Escudillas representativas de los estilos cerámicos mencionados en el texto: 1) Averías (procede del sitio Llajta Mauca), 2) Sunchituyoj (del sitio Llajta Mauca), 3) Negro sobre Rojo Brillante (del sitio Vilmer). Tomadas de Wagner y Wagner 1934. Digitalizado por Gustavo Carello.

otros montículos del sitio, que es una capa producto de actividades de consumo. La objeción de Greslebin se basa en que el material aparece en una capa de 
elemento más de unidad, ya que un depósito superior compuesto fundamentalmente de fragmentos cerámicos, por sobre el nivel de piso, y de una capa de arena, se registra en todos los casos analizados y podría remitir a nuevas actividades postocupación habitacional, según planteamos antes.

\section{Caso A.4 .Túmulo 59 (T59) del sitio Vilmer Norte (Von Hauenschild 1949, s.a.)}

- Ubicación: Ídem al T57.

- Cronología y asociación cultural: Ídem al T57.Para el T59 se refiere, específicamente, presencia de cerámica polícroma que interpretamos como Averías.

- Registro e interpretación: Von Hauenschild (s.a.: 30) dice: “...una vez despejada la cima del túmulo de arena que se había acumulado, apareció un piso, pero de dimensiones mucho mayores que el del túmulo 57, de 12 metros de largo por 4 metros de ancho, dividido en 3 secciones de 4 metros por cuatro; la del medio se elevaba 20 centímetros sobre el nivel de las otras dos... además tenía un anexo en la parte sud de aproximadamente 2 por 2 metros, donde podemos juzgar que estaba instalada la cocina por la cantidad de carbón vegetal, cenizas y amontonamiento de los más diversos restos de huesos de animales como así también de espinas de pescado...". Este caso muestra lo esencial que define a la Situación A, pero presenta diferencias de tamaño y detalles que podrían remitir a un espacio de vivienda techado más amplio y su complementación con otro menor. El registro obtenido muestra la ausencia de un patrón habitacional rígido, y lleva a pensar en un posible ajuste a la composición del grupo doméstico y/o a otras pautas socioculturales. La ausencia de hallazgo de entierros en una zanja cavada alrededor de la base del montículo, nos lleva a preguntarnos si estas diferencias no podrían vincularse a modificaciones en el tratamiento del espacio habitacional y de los muertos ${ }^{17}$ relacionadas con el proceso colonial.

\section{Situación B}

Para los 3 casos que siguen no hay indicios de pisos. En cambio, se registra una estratificación de material doméstico mediada por hiatos, en apariencia estériles, que apuntan a una situación diferente a la A, suponiendo

\footnotetext{
17 En los pueblos de indios intervenidos por la Colonia, los entierros pasan a realizarse en cementerios cristianos.
}

eventos alternados de uso y desuso que incrementaran la altura del montículo (Fig. 14).

Caso B.1. Montículo del sitio Yaso (Wagner y Wagner 1934; Vellard s.a.)

- Ubicación: Sitio del área del río Dulce cerca de Beltrán (depto. Robles) (ver fig. 1).

- Cronología y asociación cultural: Los hermanos Wagner (1934: fig. 293) ilustran una figura de un puco tipo Sunchituyoj procedente del sitio con una representación muy similar a la del recipiente de Huilla Catina asignable a la Fase Quimili Paso que señala Lorandi (1978). Se estima una cronología anterior y/o símil a la fase Quimili Paso, sin registro de material Averías.

- Registro e interpretación: Montículo de planta circular y pequeño diámetro $(10 \mathrm{~m})$ en relación a la altura $(2,50 \mathrm{~m})$. En el corte ilustrado por los Wagner se ve un núcleo estéril, y estratos horizontales sin material cultural intercalados con niveles con materia orgánica, carbón, ceniza, restos de pescado, tiestos y huesos. Vellard (s.a.: 2) refiere: “...une base homogène compacte, semblable au sol environnant, surmonté d'une couché d'épaisseur variable -20 à $60 \mathrm{~cm}$ - ou la terre paraît mélangée de matières organiques, surtout végétales, désagrégés. C'est uniquement dans ce couché supérieur que se trouvent, a des niveaux variables, des plaques de cendres et des charbons, de très nombreux os d'animaux et de fragments de céramique avec quelque petites pièces entières". La "base" homogénea parece referirse al núcleo del montículo. No hay referencias de un piso asimilable a la Situación A. Vellard señala el hallazgo de urnas funerarias en la base de los montículos.

\section{Caso B.2. Montículo del sitio Sunchituyoj (Wagner y Wagner 1934; Vellard s.a.)}

- Ubicación: Sitio de la mesopotamia santiagueña (ver fig. 1).

- Cronología y asociación cultural: Del sitio ${ }^{18}$ procede material Sunchituyoj pintado y con búhos en relieve y no se menciona Averías ni colonial. Podría ser cronológicamente acorde a las fases Las Lomas y Quimili Paso.

- Registro e interpretación: Montículo de planta oval (aprox. 12,25 x 7 m y 1,80 m de altura). Los gráficos de

\footnotetext{
${ }^{18}$ El sitio da nombre a la tradición cerámica homónima, que abarca desde un periodo medio al de contacto hispano-indígena (Reichlen 1940; Lorandi 1978), pero la ocupación de la zona pudo no haber llegado a momentos tardíos y coloniales (Reichlen 1940; Taboada y Farberman 2014).
} 


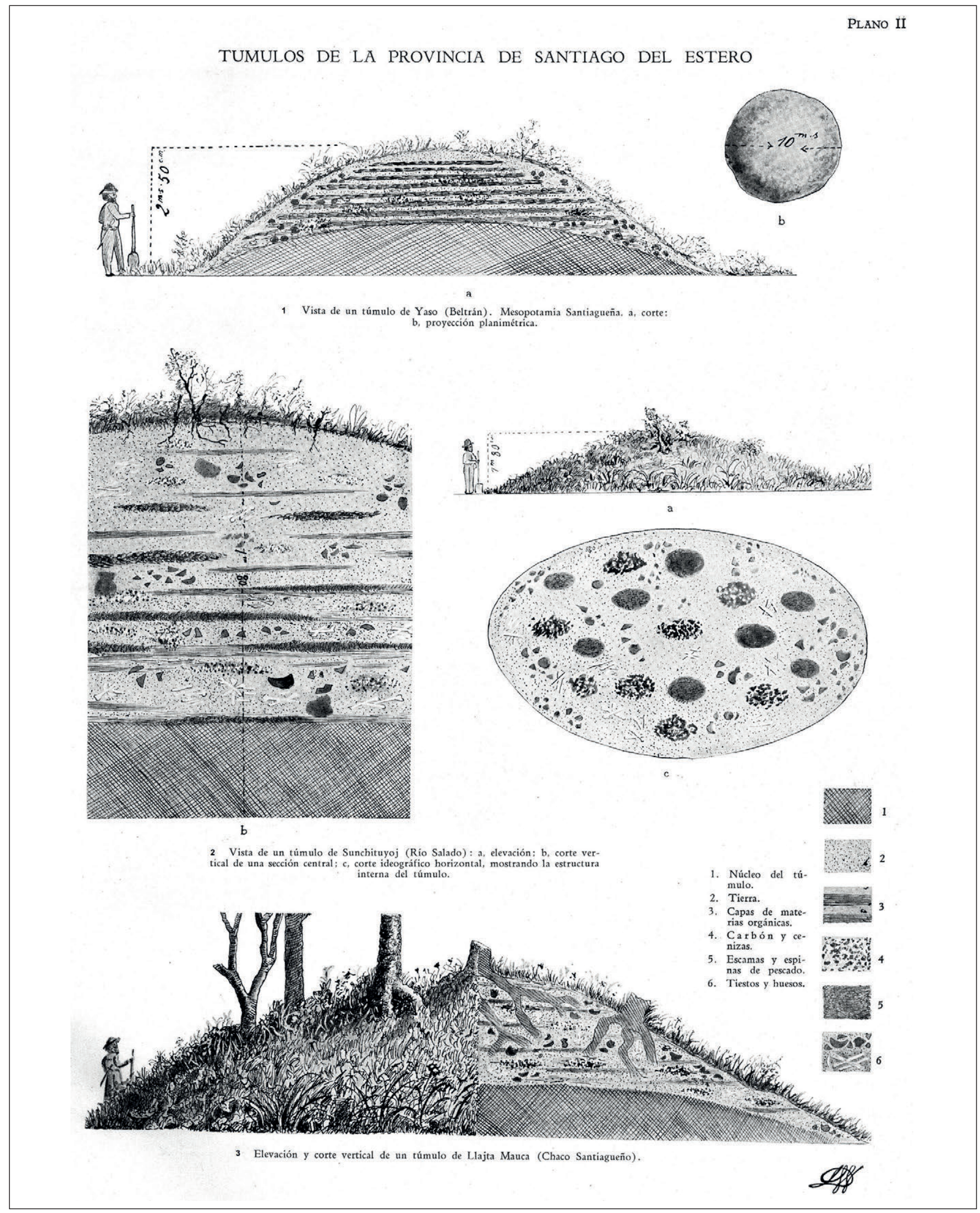

Fig. 14. Montículos de la Situación B: 1) Caso B.1. Yaso, 2) Caso B.2. Sunchituyoj y 3) Caso B.3. Llajta Mauca. Tomado de Wagner y Wagner 1934. Digitalizado por Gustavo Carello. 
los Wagner muestran un núcleo estéril, y capas discontinuas de tierra alternadas con materia orgánica, carbón, ceniza, restos de pescado, tiestos y huesos. No se ven pisos. Según Vellard, la estructura es similar al caso de Yaso, pero las capas son más gruesas y los restos se distribuyen en concentraciones de hasta $1 \mathrm{~m}$ de diámetro, lo que podría indicar áreas de actividad y/o de arroje de basura.

Caso B.3. Montículo del sitio Llajta Mauca (Wagner y Wagner 1934)

- Ubicación: Sitio del chaco santiagueño muy excavado por los Wagner (ver fig. 1).

- Cronología y asociación cultural: Lorandi (1978) asigna el sitio a las fases Quimili Paso y Oloma BajadaIcaño. Parece haber tenido larga ocupación y ausencia de intervención colonial (Taboada y Farberman 2014).
- Registro e interpretación: Altura y largo estimados: $3,28 \mathrm{~m}$ y $15,85 \mathrm{~m}$. En el gráfico de los Wagner se aprecia similar situación al montículo de Sunchituyoj.

\section{Situación C}

Una tercera situación la definimos en base a 3 montículos analizados por Lorandi $(1978,2015$, s.a.) para los que refieren pisos poco definidos y una sucesión de depósitos alterados por la construcción de rasgos de uso doméstico (Fig. 15).

Caso C.1. Montículo B5 del sitio El Veinte (Lorandi 2015, s.a.)

- Ubicación: Sitio ubicado al este del río Salado, en el chaco santiagueño (ver fig. 1).

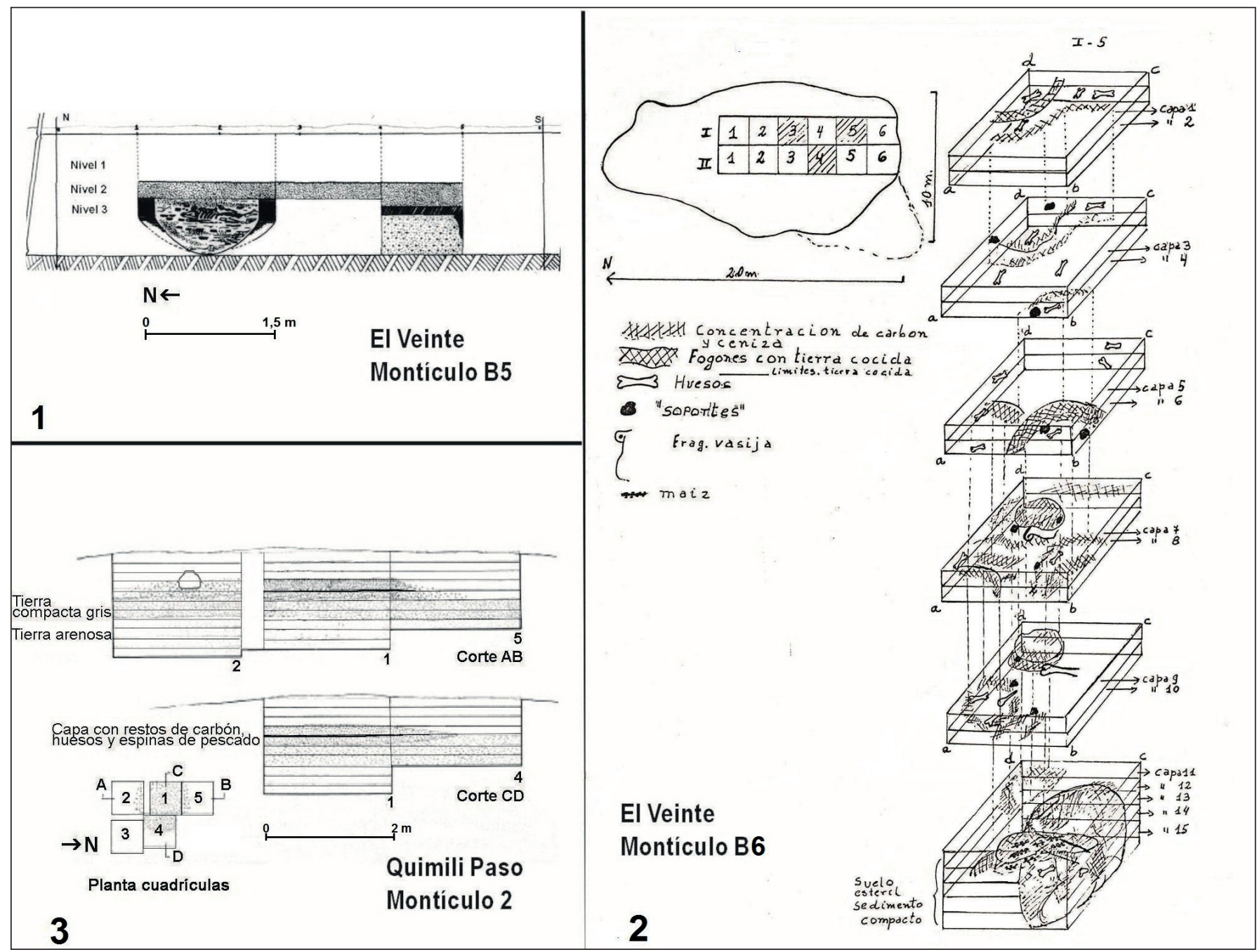

Fig. 15. Montículos de la Situación C: 1) Caso C.1. Montículo B5 de El Veinte (Lorandi 2015), 2) Caso C.2. Montículo B6 de El Veinte (esquema de campo tomado de Lorandi s.a.) y 3) Caso C.3. Montículo M2 de Quimili Paso (Lorandi 2015). Digitalizado por Gustavo Carello. 
- Cronología y asociación cultural: Sitio tipo de la Fase Las Lomas. Material exclusivo Sunchituyoj. El montículo B5 tiene un fechado de $690 \pm 90$ AP (Lorandi 1978).

- Registro e interpretación: Montículo en el que se identificaron 3 depósitos además del núcleo, que según Lorandi parece remitir a un albardón natural. Cavado en el núcleo se halló un horno de barro y paja de 1,5 m de diámetro, con restos óseos de un guanaco articulado en su interior. Cubriendo el horno y parte del centro del montículo se hallaron restos culturales $\mathrm{y}$ "consolidaciones irregulares de tierra quemada color rojiza alternando con lentes de ceniza" (Lorandi 2015: 124). Este nivel fue definido por Lorandi como un "fondo de vivienda". La autora señala que este depósito no parece haber sido alterado para incluir el horno, que sería anterior. El nivel superior se componía de sedimentos uniformes y restos culturales.

\section{Caso C.2. Montículo B6 del sitio El Veinte (Lorandi} 2015, s.a.)

- Ubicación: Ídem al montículo B5.

- Cronología y asociación cultural: Ídem al montículo B5.

- Registro e interpretación: Montículo de planta aproximadamente oval, de $20 \times 10 \mathrm{~m}$. Se excavaron 3 cuadrículas alternadas de $2 \times 2 \mathrm{~m}$, dos en el centro y otra lateral (ver fig. 15) ${ }^{19}$. En la CII-5 se halló un horno cavado en el núcleo estéril similar al referido antes. Arriba se registraron restos incompletos de otros hornos y/o fogones asociados a carbón, ceniza, huesos, bases de vasijas quemadas y soportes cónicos in situ, que Lorandi estima servían para sostén de ollas y recuerdan la igual asociación referida por von Hauenschild. Las CI-3 y CII-4 mostraron similar situación, pero también la presencia de una matriz blanquecina, consolidada "como suelo apisonado" (con poco material y algunos artefactos completos) ubicada sobre el núcleo estéril. Lorandi señala que no se pudo reconstruir material entre las 3 cuadrículas, indicando mucha dispersión. Concluimos que una parte del montículo parece haberse utilizado para acciones de preparación y cocción de alimentos, siendo periódicamente transformado mediante la construcción de hornos y fogones, mientras el sector central pudo albergar un primer piso poco definido (Lorandi 2015).

\footnotetext{
19 Agradecemos a Ana María Lorandi permitirnos publicar el esquema de campo y la información inédita (Lorandi s.a.) donde detalla la excavación según 15 niveles de $10 \mathrm{~cm}$.
}

Caso C.3. Montículo M2 del sitio Quimili Paso (Lorandi 1978, 2015)

- Ubicación: Sitio de la mesopotamia santiagueña, sobre el río Mailín (ver fig. 1).

- Cronología y asociación cultural: El montículo registra material Sunchituyoj y mínima presencia de Averías. Cuenta con tres fechados: $590 \pm 60$ AP, 750 $\pm 70 \mathrm{AP}$ (ambos para la C1, capa 4) y $1140 \pm 60 \mathrm{AP}$ (para la C2, capa 4) (Lorandi 1978, 2015). Lorandi lo atribuye a la Fase Quimilí Paso.

- Registro e interpretación: Montículo de 0,80 m de altura. Se excavaron varias cuadrículas en el sector más alto. Presentó un depósito superior de 0,50 m donde el material cultural era más abundante y se prolongaba por la periferia hasta los $0,90 \mathrm{~m}$ de profundidad. No hay indicación de un piso compacto y bien definido, pero sí de un "fondo de vivienda" a una profundidad de $0,80 \mathrm{~m}$, desplazado hacia la periferia del montículo, situación que Lorandi (2015) atribuye a cambios en el emplazamiento de la vivienda o de los fogones, de forma similar a lo que ocurre en el sitio El Veinte. En el montículo se hallaron una vasija boca abajo y una variada e importante cantidad de artefactos completos y fragmentados ${ }^{20}$ que remiten a actividades domésticas.

\section{DISCUSIÓN}

\section{Sobre lo morfológico-funcional: configuración de los espacios domésticos}

Sintetizando, podemos asignar la Situación A a espacios estables de habitación. Según las evidencias arqueológicas, es factible plantear la existencia de viviendas techadas y cerradas lateralmente, con superficies de cerca de $30 \mathrm{~m}^{2}$ y hasta $60 \mathrm{~m}^{2}$ y posibilidad de divisiones internas según el caso del T59. Las mismas remiten a ámbitos interiores afines al resguardo de personas y bienes, en tanto hay presencia de restos de techo y pisos bien delimitados, posiblemente preparados, con escaso material cultural y sin registro de fogones ni otros rasgos que pudieran adscribirse a áreas de actividad al interior (como preparación de comida o manufactura). Esto es consistente con el modelo que exploramos y con las prácticas habitacionales tradicionales. Las medidas también son asimilables a los espacios

\footnotetext{
${ }^{20}$ Torteros, vasijas en miniatura, cuentas, hueso trabajado, láminas de arenisca, lascas de cuarzo, puntas de proyectil de hueso y piedra, además de 11.189 fragmentos de cerámica y gran cantidad de huesos de fauna.
} 
de habitación actuales, donde el tamaño está dado, en última instancia, por la luz posible de cubrir con las maderas disponibles. Algunos indicios dejan abierta la posibilidad de reclamación de materiales y reacondicionamiento de espacios para nuevos usos. La Situación A estaría registrada, por ahora, para época prehispánica tardía y colonial, con amplia distribución territorial dentro de Santiago del Estero (río Dulce medio, río Salado centro-sur y chaco santiagueño norte).

Una forma rectangular de planta parece poder derivarse del registro arqueológico y pensarse como lógica en función de la tradición constructiva ortogonal de la región. La cuestión se abre en cuanto a la forma elíptica del piso registrado por Greslebin, que se aparta de los demás pero se corresponde con la única referencia documental conocida que menciona la forma de las viviendas de la región ${ }^{21}$. Sin embargo, la referencia a que eran casas muy grandes no parece aplicable al caso. Nos preguntamos si el cronista pudo haber descripto construcciones de otro tipo que las que el registro arqueológico da cuenta hasta ahora. La cita también podría hacer alusión a una configuración oval del espacio doméstico vinculada a la forma que adoptan los montículos. De todos modos, cabe dejar abierta tanto una variante en la forma de las viviendas, como otra función para el caso de Colonia Chilca — como supone el autor-, aunque el resto de los elementos en común parecen dar unidad funcional habitacional a los distintos casos.

Respecto de la recurrente práctica de inclusión de un recipiente bajo los pisos de la Situación A, se podría especular con algún tipo de acto fundacional vinculado a los ancestros (al menos en un caso se trata de una urna, en otro parece contener ceniza y, de hecho, los núcleos de los montículos son receptores de entierros) anterior a la construcción habitacional, una práctica prehispánica común en Sudamérica. Lo dicho permite avanzar por sobre la simple propuesta morfológica y de eficiencia para visualizar otros aspectos significativos en la configuración del espacio doméstico.

Ahora bien, que los autores se concentraran en describir el bien definido piso central de la Situación A, con falta de detalles para el área circundante, impide evaluar potenciales usos dados a esta última, específicamente si acogió el desarrollo de actividades complementarias y rasgos asociados en áreas extramuros o parcialmente cerradas y de estructura independiente a un espacio techado principal. Los casos de SV150 y SV157 (que

${ }_{21}$ "Las casas tienen grandes y redondas los pueblos muy juntos" (Cieza [1553] 1947 en Lorandi 2015:99). tomamos por compartir tanto el sitio como la ubicación cronológica-cultural de la Situación A) tampoco resultan determinantes, ya que ambos montículos presentan una importante área no excavada que podría dar cabida a diversas construcciones, rasgos y áreas de actividad. Aun así, la referencia a una posible "cocina" separada en el T59 y la distribución fuera del área de piso y de techo de ciertos depósitos y materiales en los otros montículos analizados para la Situación A, permiten pensar la complementariedad de actividades en un mismo montículo en relación a dicha situación. Que el área que ocupa el piso sea relativamente chica en relación al tamaño del núcleo de base también apoya la idea.

De todas formas, es la situación que describe Lorandi (Situación C), la que más claramente muestra el otro aspecto que nos interesa del modelo: espacios donde se desarrollan actividades cotidianas -fundamentalmente las vinculadas al fuego, cocina y descarte- y que parecen poder corresponder a lugares externos con alguna formalización (como la construcción de hornos y fogones), con cierta sectorización en su ubicación, recurrencia de uso y refacciones, y áreas asignables a pisos poco definidos. Sin embargo, no tenemos por el momento ningún indicio para plantearlos como espacios complementarios a los contextos interpretados como techados de la Situación A, a lo que se suma que el escenario cronológico-cultural es diferente. Para los montículos y sitios que estudia Lorandi no hay registro de evidencias de instalación del tipo A. Pero tampoco contamos para dichos casos - ni para otros de situación cronológica cultural análoga- con algún otro tipo de registro residencial. Como sea, a pesar de la ausencia de indicadores de alguna construcción habitacional, Lorandi $(1978,2015)$ concluye, en base al contexto general, que los montículos excavados correspondían a situaciones de "viviendas-basurero", señalando que ciertas capas más definidas — por el tipo y disposición de sus restos - dentro de la secuencia de disrupciones podían constituir "fondos de vivienda". Los datos analizados y la divergencia socio-histórica en relación a la Situación A habilitan explorar la idea de que estos contextos pudieran contar con un tipo de cobijo diferente, y que este fuera más precario y/o menos estable. Recordemos la presencia de niveles y espacios un poco más consolidados, sin definición clara de forma, con restos materiales diferentes a los asociados a comida y fuego, insertos en espacios centrales cercanos a la distribución de los indicadores de actividad y rasgos antes referidos, que se ubican, en cambio, más lateralmente. Esto nos muestra, 
al menos, un uso diferenciado de dichos sectores, y permite pensarlos como posibles indicios de áreas techadas no muy grandes y de poca definición arqueológica — sea por su poca formalización, su perecibilidad y/o su baja estabilidad de uso- estrechamente relacionadas con las áreas de actividad culinaria a su alrededor. Por su parte, es significativo notar que las 3 dataciones realizadas por Lorandi $(1978,2015)$ sobre un mismo montículo (M2 de Quimili Paso) dieron fechas que cubren un amplio rango, con mayor cercanía cronológica entre las obtenidas en la misma cuadrícula y nivel que con aquella de la cuadrícula inserta en un área más marginal. La situación plantea un uso del espacio mediado por tiempos considerables, aun cuando no hay referencias a niveles estériles. Como señala Lorandi, la dinámica temporal se puede apreciar, más bien, en la superposición, refacción, corrimiento y alteración de los contextos culinarios y de desecho que como una estratificación de niveles de uso. Ahora bien, no es posible condicionar la construcción de nuevos hornos a un reemplazo por su afección, ya que en un mismo montículo se han hallado hornos completos con otros hornos y/o pisos por encima. En razón de ello, habrá que pensar en que un mismo espacio es reusado varias veces. Por el momento no contamos con evidencias para evaluar si se trata de reúsos dado al lugar por movilidad intrasitio o intersitio, ni si hubo etapas de desocupación o sólo de reconfiguración del espacio.

Por su parte, la Situación B también remite a depósitos de desechos y rastros de actividades fundamentalmente culinarias, dentro de contextos poco o nada formalizados, y sin indicios de construcciones asociadas. En un principio la diferenciamos de la Situación C, por la aparente ausencia en la Situación B de pisos o niveles de uso, de rasgos domésticos y de referencias de refacción, y por la presencia de capas estériles. Sin embargo, la poca formalización, la recurrencia de usos y la ausencia de registro de arquitectura habitacional asociable a estos contextos podrían representar un escenario semejante o complementario al de la Situación C, que cobra mayor lógica en la similar cronología, asociación cultural y distribución territorial (ambas registradas en la mesopotamia central y en el chaco santiagueño central sin - hasta ahora - registro de Situación A en esas zonas) entre los contextos de ambos casos. Uno y otro remiten a similar tipo de actividades, a instalación de cierta precariedad, y a plantearnos posibles alternancias de uso y reúso, aunque en la Situación B habría más indicios para pensar en abandono y retorno (niveles estériles y capas de arena).
$\mathrm{Al}$ respecto cabe analizar también el "crecimiento" de los montículos de tipo B y C, lo que podría aportar a sostener interrupciones de uso de los mismos ${ }^{22}$. Desde nuestra lógica es de suponer que las acciones realizadas en áreas de actividad no generen un crecimiento del nivel de piso sobre el que se actúa diariamente, a diferencia de los depósitos de desechos. En cambio, períodos de desuso o desocupación (sea por abandono temporal del espacio o por remodelación) darían cuenta tanto de la necesidad de reacondicionamiento repetido de espacios de instalación y de rasgos como los señalados por Lorandi ${ }^{23}$, de acumulaciones de basura y de sedimentos (muchas veces arena en los casos analizados) de forma natural o intencional para reacomodar el lugar, y/o de hiatos estériles entre usos. Ya vimos cómo el cubrimiento con arena es lo que "cierra" los niveles de ocupación en la Situación A que, como hecho natural — desbordes fluviales - o antrópico — arroje intencional—, podría remitir a un hecho o práctica común de clausura del espacio de habitación también en los otros casos.

Por fin, como señala Lorandi (1978, 2015), el espacio doméstico parece completarse con un tercer ámbito - común para las situaciones $\mathrm{A}, \mathrm{B}$ y $\mathrm{C}$ - : el destinado a los muertos, ubicado siempre alrededor de la parte baja de los montículos y también en el núcleo mismo. Los dibujos y referencias de los diversos autores muestran que las urnas y entierros directos se insertan bajo la capa superior postocupación, sin referencia a cortes en la misma, por lo que habría que asumir que, al menos en algunos casos, su disposición pudo darse antes, durante o inmediatamente después del período de uso habitacional. Más aun, la inclusión de entierros directos lleva a pensar que todo el proceso funerario, hasta la reducción secundaria, se hacía quizás dentro del mismo espacio. La urna bajo piso con restos humanos (a la que posiblemente se suman las dos escudillas, una potencialmente contenedora de ceniza, en la misma disposición) para la Situación A, indicaría la participación de los muertos en la vida doméstica desde un inicio de la instalación, al menos en estos casos. Paralelamente no hay que olvidar la referencia de von Hauenschild (1949), y también una de Reichlen (1940), sobre la posible función específicamente ritual de algunos montículos.

22 Por el contario, en los montículos de la Situación A es claro que su formación sobre el núcleo de base se debe al derrumbe de las construcciones, más acumulaciones de desechos posteriores al uso.

23 "El horno, al ser abandonado, se rompía y rellenaba, porque había sido cavado en sedimentos culturales menos consolidados que el terreno basal estéril. Este mecanismo fue el responsable de la considerable alteración de la estratigrafía natural que se observó en las excavaciones" (Lorandi 2015:127). 
Sin embargo, dado que en los montículos de referencia los restos adscriptos a esta actividad parecen estar en la capa postocupación habitacional, se podría concluir que los mismos remiten, más bien, a nuevas funciones dadas al espacio posteriormente al uso y abandono como lugar de habitación. Las inhumaciones directas podrían suponer, así, el retorno para su reducción, y los materiales de la capa superior vincularse a remociones y ritos en relación a ello.

\section{Sobre lo cronológico-cultural: ¿Modos de habitar diferenciados?}

Articuladamente al estudio morfológico funcional, nos interesa ahondar en lo que parece ser una distinción cronológica-cultural entre las situaciones analizadas y que podría afianzar los contrastes en los modos de instalación que se vislumbran entre las situaciones A y B/C para explorar potenciales diferencias en los modos de habitar. Al respecto, fue sugerente reconocer que la que definiéramos como Situación A sólo ha sido registrada en asociación a contextos que involucran alfarería Averías y paralelamente se halla ausente en contextos sin Averías y con cerámica Sunchituyoj. A partir de ello nos preguntamos si el desarrollo de este tipo de instalación se pudo dar de forma concomitante con la emergencia de cerámica Averías en la región, y vincularse al proceso, poblaciones y tradiciones culturales involucradas en el mismo.

La problemática se vincula, en primer lugar, a la divergencia que los Wagner (1934) señalaran en el contenido - no es su estructura, que no analizaron- entre montículos con material asignable a tradición Sunchituyoj y Averías. A pesar de ello, hasta ahora el espacio habitacional no había sido analizado en función de esta diferenciación. Estos autores distinguieron dos grandes grupos cerámicos asociados a otros elementos culturales específicos: las Ramas A y B de su Civilización ChacoSantiagueña, esencialmente correspondientes con las posterior clasificación de Reichlen (1940) en Averías y Sunchituyoj respectivamente. Lo más interesante es que aislaron no solo materiales y sitios diferenciados para cada una de ellas, sino que insistieron en la existencia, dentro de ciertos sitios, de montículos asociados a uno y otro contexto, planteando que podrían dar cuenta de grupos distintos en lo ideológico o social, pero no en lo político dada su coexistencia. Aun cuando no pusieron en juego la potencial no contemporaneidad de ambas ocupaciones, la situación resulta inquisitiva y Lorandi la retoma y piensa en otros términos.
A partir de su propio planteo, que veía en la cerámica Sunchituyoj caracteres chaqueños locales y en la Averías elementos más altiplánicos y exógenos, de la comprobación de la coexistencia en cierto tiempo y espacio de ambas tradiciones alfareras, de la perduración de ambas hasta la Colonia, y de las referencias documentales que apuntaban al carácter multiétnico de la región, Lorandi $(1978,2015)$ se pregunta si no habrían existido asentamientos biétnicos. Pone en juego en su hipótesis otros elementos más, como son los importantes cambios tecnológicos, económicos e ideológicos (auge de hilado, desarrollo agrícola, importante manejo del agua, cambio en la representación del búho, aumento demográfico) que se dan de forma concomitante a la emergencia y afianzamiento de la nueva tradición alfarera Averías, bien diferenciada tecnológica y estilísticamente de la preexistente (Lorandi 1978). A partir de semejanzas que ve en relación a la cerámica de Bolivia, plantea que su desarrollo en la llanura santiagueña podría tener que ver con grupos de dicha región que se pudieran haber vinculado con las poblaciones de tradición local, que hasta ese momento se situaban en contextos socioculturales más dependientes del monte y el río, con una economía fundamentalmente extractiva $(1978,2015)$. Y dice: "Uno de los nudos de esta interrelación se encuentra posiblemente en la Fase Quimilí Paso. Muchos elementos invitan a pensar que es entre los años 1200 y 1400 cuando se inician los contactos más constantes y densos entre los portadores de las Tradiciones Sunchituyoj y Averías" (Lorandi 2015: 154). Es significativo recordar que todos los casos conocidos de nuestra Situación A pueden ser referido a esta fase o posteriores, mientras no hay referencias de ella para sitios, contextos ni fases anteriores. La idea se apuntala con la referencia de Reichlen de que los montículos de la región mesopotámica (donde se ubican tanto sitios asignados a las Situaciones $\mathrm{B}$ como $\mathrm{C}$ y ninguno de la A) muestran diferencias en los materiales, disposición, base y tamaño en relación a los de los Bañados de Añatuya. Y aunque el autor señala similar estructura general que los de "Industria Averías", no menciona pisos del tipo A como sí lo hace para Cayo López (que compara con los de Greslebin y von Hauenschild y con los de la zona de Icaño en los Bañados de Añatuya, donde se inserta SV150), por lo que parece evidente que no dio con ellos en la mesopotamia santiagueña. Paralelamente, von Hauenschild (s.a.) expresa que dentro de la variedad de montículos y cerámica de Vilmer Norte - que incluye Averías y Sunchituyoj— los montículos artificiales y con piso como los del T57 y 
T59 se asocian a cerámica Averías. Por último, la única referencia de Lorandi (1967) para un montículo asociado a cerámica Averías, ubicado en Icaño (de la fase más tardía Oloma Bajada-Icaño), concluye que tuvo una única ocupación (asimilable a la Situación A).

A lo dicho parece posible establecer otra diferencia en relación al origen antrópico o natural del núcleo de base. Según la determinación de los diversos autores, los montículos asociados a situaciones $\mathrm{B} / \mathrm{C}$ se resuelven sobre albardones o suelos naturales, mientras que al menos algunos de la Situación A pueden ser interpretados como artificiales. Aunque esto requiere mayor estudio y constatación, y además puede tener que ver con posibilidades del ambiente de inserción, su elección misma también puede ser significativa como modo cultural. Más aun, pensar que son los montículos más tardíos y asociados a grupos con mayor desarrollo socio-económico y estabilidad los que pudieran ser construidos, tiene lógica. Esto se vincula a su vez a la posibilidad de modelación general del paisaje tardío que parece poder derivarse de ciertas referencias de las crónicas y que parece vislumbrarse concretamente en relación a Sequía Vieja (Ortiz y Fernández 2014) donde se inserta un caso A.

La pregunta final, entonces, es si la ausencia de pisos y de espacios techados definidos en los contextos asociados a cerámica Sunchituyoj y momentos anteriores a la irrupción de Averías, podría ser indicativa no solo de un tipo de cobijo diferenciado, sino de un modo de habitar distinto. Tengamos en cuenta la intensa refacción de rasgos y discontinuidades señaladas por Lorandi y el amplio rango temporal obtenido para un montículo de tipo $\mathrm{C}$, así como los hiatos aparentemente estériles de los gráficos de los Wagner para la Situación B. Vellard (s.a.) se plantea, de hecho, que estos casos pudieran tener que ver con retornos de los habitantes al mismo punto con períodos de desocupación marcados por la acumulación de arena (que vimos podría considerarse un indicador de cierre de instalación). Recordemos también que para las Situaciones B y C, o contextos cronológicosculturales equivalentes, no contamos con ningún registro que pueda dar cuenta de construcciones, lo que ya definiría un modo de refugio diferente sobre el que ignoramos sus características. Esta ausencia de registro hace pensar en tecnologías más perecederas, que dejaran huellas menos firmes. Por su parte, referencias a sectores de pisos más limpios y no muy definidos - como los únicos referentes posibles de asimilar a ambientes de resguardo personal-, muy directamente asociados a áreas de actividad removidas y superpuestas, permiten pensar en una organización del espacio y actividades menos formalizada, además de una estrecha vinculación espacial y social entre actividades y entre personas. Se ponen de relieve así que las diferencias reseñadas podrían ser indicativas de modos de habitar diferenciados, donde la permanencia y la formalidad de instalación de la Situación A se contraponen a la informalidad, la remodelación, la recurrencia y la perecibilidad de las situaciones B/C. Estas últimas podrían dar cuenta de diversos eventos de uso y reconfiguración de un mismo espacio. La cuestión se plantea sobre si esto se dio dentro de un proceso de habitación continuo, donde cada tanto se originaban nuevos rasgos y lugares de cobijo (dadas, por ejemplo, su perecibilidad o inundaciones) que era reubicados parcialmente corridos y separados de la ocupación anterior por aportes naturales o antrópicos de arena o sedimento, o si las nuevas ocupaciones implicaron tiempo de desuso, abandono temporal del espacio, y reocupación posterior. La falta de excavaciones actuales en este tipo de contextos deja, por el momento, planteada ambas opciones. Sin embargo, en cualquier caso, se trataría de modos de habitar y organizar el espacio diferenciados a la Situación A. Más aún, la opción de desocupaciones temporales sería afín a un modo de vida menos estable, consistente con el amplio rango aportado por los 3 fechados en un mismo montículo y con la situación sociocultural definida por Lorandi para las fases correspondientes, con alta interacción con el ambiente natural. De hecho, todos los ejemplos analizados para la Situación B/C remiten a momentos o contextos con una importante presencia de instrumentos y restos de caza y pesca y escasas evidencias de maíz sin capacidad de sostén alimenticio (Lorandi 1978, 2015), por lo que no sería ilógico pensar en grupos con cierta necesidad o tradición de circulación por el monte pero con retorno a los mismos poblados (Taboada 2016). A ello se suman las posibles movilizaciones vinculadas a inundaciones y sequías, que podrían haber sido menos controlables si pensamos la hipótesis de una menor capacidad de modelación del terreno y manejo del agua para estas poblaciones. Inundaciones acotadas, deterioro de las viviendas u otras causas pudieron también generar movilizaciones y rotaciones de instalación intrasitio, tal como se hace actualmente refuncionalizando los espacios desocupados. Procesos de reformulación de usos del espacio, variando entre áreas de instalación techada y exterior, son una práctica generalizada en la actualidad al caer o desarmar viviendas e instalarlas a pocos metros dentro del mismo ámbito de residencia, implicando arreglo de pisos, reutilización de maderos y descarte in situ de materiales no reutilizados de la vivienda colapsada, como también nuevos circuitos de tránsito, desecho y actividades, pero 
que conservan el funcionamiento del resto de los ámbitos y la actividad general en el espacio doméstico.

La diferenciación expuesta remite, por último, a la posibilidad de conjugarla con la polarización que, aunque estereotipada, vieron los cronistas en los habitantes de la llanura santiagueña, caracterizados por la historiografía como "alarabes sin casa" (nómades) a unos y sedentarioslabradores a los otros. Una distinción que nos venía interpelando por la aparente ausencia de registro arqueológico que diera cuenta de ella, además de por los presupuestos que implicaban caracterizaciones tan taxativas (Farberman y Taboada 2012; Taboada y Farberman 2014; Taboada 2016). Aun cuando estamos ante el panorama expuesto para momentos de contacto hispano indígena para el que no tenemos aún identificadas Situaciones B/C, no es imposible su existencia o una situación derivada de ella, pensando en la posibilidad de continuidad de ciertas prácticas con base en una tradición de fondo diferenciada y de la pluralidad percibida por los cronistas. Arqueológicamente no es descartable, porque Lorandi comprobó la perduración de Sunchituyoj — como referente material asociable a la Situación B/C - hasta la Colonia. A ello se suma que la calibración actual de los fechados amplía los rangos temporales y, al menos, uno de Quimili Paso donde se da una Situación C podría llegar al momento de contacto hispano (Taboada y Farberman 2014). Además hay sitios que presentan ambos tipos de evidencias que no están ni datados ni estudiados modernamente. De hecho, al menos Llajta Mauca, con un montículo de la Situación $\mathrm{B}$, presenta elementos de la fase Quimili Paso pero con continuidad hasta la fase pericolonial de Oloma BajadaIcaño. Como vemos, el problema parece más bien vincularse a una cuestión cultural que estrictamente temporal.

Por último, de una lectura global concluimos que, a la par de los elementos específicos señalados, se dan también pautas comunes en la configuración del espacio de habitación. Estas hacen a cuestiones generales y permiten pensar en una tradición de instalación compartida. Engloban el establecimiento sobre montículos, el cierre de ocupaciones por capas de sedimentos, la reutilización de montículos para nuevos usos, la configuración de espacios de desecho y preparación de fuego y comida como lugares particulares y la inhumación en el espacio doméstico (salvo quizás para época colonial). Todas las diferencias pueden entenderse, en cambio, en relación específica a la estabilidad de la instalación, lo que es consistente con las características económicas y sociales que la arqueología puede adscribir a los contextos cronológicos culturales asociados, y eventualmente también a las referencias de las fuentes coloniales.

\section{PARA CERRAR}

Creemos que un aporte de esta investigación es la posibilidad de señalar, por primera vez en la arqueología local, un modelo de vivienda prehispánica para los habitantes de la llanura santiagueña. Basado en la Situación A, sería aplicable — por ahora- a momentos prehispánicos tardíos y coloniales, con amplia distribución territorial, y no excluye la posibilidad de otros modos de instalación contemporáneos. Articuladamente cabe admitir un modelo básico de distribución de actividades (interior-exterior) en la conformación de los espacios de habitación, y plantear al menos dos formas de resolución en aparente concordancia con dos escenarios socioculturales y con dos potenciales modos de construir (y quizás aún de habitar) el espacio doméstico respectivamente. Estos se muestran más claramente diferenciados en relación a dos momentos, pero nada implica la necesaria suplantación de uno por otro. Por el contario, algunos datos podrían apuntar a su coexistencia en cierta época. Esta propuesta se basa en la tendencia observada en los datos y casos conocidos, que no son muchos, por lo que se requerirá de nuevas situaciones para afinarla o rechazarla. La confirmación de un modo de habitar espacialmente discontinuo implicaría un cambio importante en la conceptualización arqueológica que hasta el momento se tenía de las poblaciones agroalfareras tardías de Santiago del Estero, para empezar a pensar en grupos quizás parcialmente móviles, en las prácticas que los constituyeron e interrelacionaron con otros, y en los indicadores arqueológicos que pudieran dar cuenta de su idiosincrasia. A su vez, nos requerirá la discusión y re-conceptualización de categorías estereotipadas, limitantes y cargadas de sentidos definidos para otras realidades, tales como sociedades simples o complejas, nómades o sedentarias (Dillehay 2013, entre otros), y que en sus definiciones más tradicionales y cerradas no pueden ser directamente extrapoladas a las situaciones expuestas.

Por su parte, las prácticas y características socioculturales que la arqueología parece poder adscribir a cada uno de estos dos modos de instalación presentan puntos en común con la diferenciación básica que los conquistadores españoles hicieron de las poblaciones de la región al entrar al territorio provincial. Esto nos interpela sobre su posible identidad de origen y sobre los procesos de constitución y mutuo relacionamiento a lo largo de su historia, sobre los que la arqueología y la historia vienen preguntándose (coexistencia, integración, fusión y diferenciación de identidades, alianza, 
conflicto, enemistad). Para ello habrá que salvar problemas arqueológicos, cronológicos, de definición y de relectura de fuentes que hace un tiempo intentamos hacer de forma interdisciplinaria (Farberman y Taboada 2012; Taboada y Farberman 2014), y que buscaremos hacer con este aspecto en particular.

Finalmente, cabe decir que la caracterización lograda y las interpretaciones generadas podrán resultar significativas no solo a nivel local y regional, sino también macro-regionalmente. Por un lado, al ampliar el conocimiento sobre la distribución, características y variantes de las formaciones monticulares dentro de Sudamérica con el caso de Santiago del Estero, escasamente conocido extra-localmente. Por otro, por el enfoque (tanto a nivel de objetivos como en la propuesta de abordaje) hacia los aspectos arquitectónicos y espacios domésticos, poco estudiados desde esta perspectiva para la problemática señalada, y que aporta otra forma de acceso a una práctica de instalación generalizada macro-regionalmente.

Puntos a resolver, quedan varios. De hecho, nuestro trabajo ha sido más bien el armado de una problemática y el planteo de preguntas e hipótesis. Quedan como problemas puntuales con implicancias generales para la interpretación y que requieren de nuevos datos de campo para ser profundizados: definir el grado y diversidad de acción antrópica que pudo mediar en la configuración de los núcleos de los montículos y en la modelación del terreno en general; afinar los procesos de constitución de niveles estériles de arena, de los contextos culinarios derruidos y de los depósitos superiores de los montículos; ajustar observaciones sobre posibles indicadores de construcciones residenciales para las Situaciones B y C; determinar la relación estratigráfica y cronológica de los contextos funerarios insertos en montículos habitacionales; y estudiar patrones de deterioro (derrumbe natural o provocado, reutilización de materiales, reinstalaciones) que pudieran dar cuenta de los procesos e historia que sufrieron las viviendas, sus usuarios y el asentamiento que los reunió. Con base a ello podremos comenzar a analizar diversidades o recurrencias al interior de grupos domésticos y socioculturales en relación a composición, prácticas y formas de vida en ambos niveles de organización social y para diferentes situaciones históricas.

\section{AGRADECIMIENTOS}

Hoy no estaría abordando este tema si, hace años, Ana Teresa Martínez no me entusiasmara con él, si luego Ana María Lorandi no me incentivara para seguir, si antes Axel Nielsen no me diera herramientas de trabajo y si Carlos Angiorama no hubiera estado todo el tiempo al lado mío. El artículo se ha nutrido de conversaciones sostenidas con ellos y con Judith Farberman, Patricia Cuenya, Mirian Collantes y Guillermo Ortiz, a quienes agradezco sus aportes y libero de responsabilidad sobre la interpretación final. Gracias también a Diego Argañaraz Fochi, María José Barazzutti, Florencia Becerra, Andrea Bertelli, María Domínguez, Florencia Finetti, Melissa Gallardo, Carlos Juárez, Jimena Medina Chueca, Guillermo Ortiz, Josefina Pérez Pieroni, Silvina Rodríguez Curletto, Bruno Salvatore, Santiago Savino y Sebastián Silvestri por su ayuda en el campo y el gabinete. A Paz Núñez Regueiro agradezco la ayuda en la consulta del Archivo del Musée du Quai Branly, y a Gustavo Carello la edición de las imágenes. Un especial agradecimiento para Don Luis Silva, Doña Margarita, Nicolás, Candelaria, Vanesa, Evelyn, Andrea y Daniel por su hospitalidad y por el consentimiento para publicar las fotografías de su vivienda. Al director del Museo Wagner, Andrés Chazarreta, agradezco los permisos de trabajo, y al intendente de Colonia Dora, Juan Sequeira, su apoyo. La investigación se hizo con financiamiento PIP CONICET 11/265, PICT ANPCyT 1021 y PIUNT 26G/502.

\section{FUENTES PRIMARIAS}

Lorandi, A. M. s.a. (197?): Informe inédito. Archivo personal de la autora. Ms.

Nielsen, A. 2000: "Andean caravans: An ethnoarchaeology". Ph. D. Dissertation. University of Arizona, Tucson. Ms.

Taboada, C. 2003: "Arquitectura y Sociedad en la Quebrada de Humahuaca Prehispánica". Tesis doctoral. Facultad de Ciencias Naturales (UNT), San Miguel de Tucumán. Ms.

Vellard, J. s.a. (1933?): “Argentine. Archéologie de Santiago del Estero". Archives du Musée du Quai Branly. Fonds Henry Reichlen. Dossier (11797) DB000468. Ms.

Von Hauenschild, J. s.a.: "Vilmer Norte". Fondo Documental Jorge von Hauenschild, Museo de Antropología, Facultad de Filosofía y Humanidades, Universidad Nacional de Córdoba: https://rdu.unc.edu.ar/handle/11086/1145. Fecha de visita 22/07/2015. Ms.

\section{BIBLIOGRAFÍA}

Adams, E. 1983:"The architectural analogue to Hopi social organization and room use, and implications for prehistoric northern southwestern culture". American Antiquity, 48, pp. 44-61.

Angiorama, C. y Taboada, C. 2008: "Metales andinos en la llanura santiagueña (Argentina)". Revista Andina, 47, pp. 117-150.

Ashmore, W. y Wilk, R. 1988: "Household and community in the Mesoamerican past", en Ashmore y Wilk (eds.), Household and community in the Mesoamerican past, pp. 1-27. University of New Mexico Press, Albuquerque.

Barreto, C. 2006: "Caminos a la desigualdad: perspectivas desde las tierras bajas de Brasil", en Gnecco y Langebaek (eds.), Contra la tiranía tipológica en Arqueología, pp. 1-29. Uniandes, Colombia.

Blanton, R. 1994: Houses and households: A comparative study. Plenum, New York. Bonomo, M., G. Politis y C. Gianotti. 2011: "Montículos, jerarquía social y horticultura en las sociedades indígenas del Delta del río Paraná (Argentina)". Latin American Antiquity, 22, pp. 297-333.

Borrero L. y Yacobaccio, H. 1989: "Etnoarqueología de asentamientos Aché. Cazadores-recolectores del Paraguay oriental". Journal de la Société des Américanistes, Tome 75, pp. 7-33.

Cabrera Pérez, L. 2013: "Construcciones en tierra y estructura social en el sur de Brasil y este de Uruguay (Ca. 4000 a 300 a. A.P.)". Técne. Perspectivas Arqueológicas: antropologia, história e arqueociências, V. 1, $\mathrm{N}^{\circ} 1$, pp. 25-33. 
Di Lullo, O. 1943: El Folklore de Santiago del Estero, Sección Folklore, Publicación III. Universidad Nacional de Tucumán, Santiago del Estero.

Di Lullo, O. y Garay, L. 1969: "La vivienda popular de Santiago del Estero". Cuadernos de Humanitas, 32, pp. 1-88.

Dillehay, T. 2013: "Sedentarismos y complejidad prehispánicos en América del Sur". Intersecciones en Antropología, 14 (1), pp. 29-65.

Erickson, C. 2000: "Lomas de Ocupación en los Llanos de Moxos", en D. Coirolo, A. y R. Bracco Boksar (eds.), Arqueología de las Tierras Bajas, pp. 207-226. Universidad de Pennsylvania-Comisión Nacional de Arqueología, Philadelphia-Montevideo.

Farberman, J. y Taboada, C. 2012: "Las sociedades indígenas del territorio santiagueño: apuntes iniciales desde la arqueología y la historia". Runa 33 (2), pp. 113-132.

Frenguelli, J. 1940: "El ambiente geográfico". Relaciones, II, pp. 13-33.

Gianotti, C. y Bonomo, M. 2013: "De montículos a paisajes: procesos de transformación y construcción de paisajes en el sur de la cuenca del Plata". Comechingonia, 17 (2), pp. 129-164.

González Ruibal, A. 2003: La experiencia del otro. Una introducción a la etnoarqueología. Editorial Akal, Madrid.

Greslebin, H. 1934: "Sobre la antigüedad de la llamada civilización chacosantiagueña (República Argentina)", Actas y trabajos científicos del XXV Congreso Internacional de Americanistas, T. II, pp. 57-74. Universidad Nacional de La Plata., Buenos Aires.

Hernando, A. 1995: "La etnoarqueología hoy: una vía eficaz de aproximación al pasado". Trabajos de Prehistoria, 52 (2), pp. 15-30.

Kent, S. (ed.). 1990: Domestic Architecture and the use of space. Cambridge University Press, Cambridge.

Lorandi, A. M. 1967: "Noticia sobre las excavaciones en la región de Icaño, en el río Salado, Santiago del Estero". Actualidad Antropológica, 1, pp. 31.

Lorandi, A. M. 1974: "Espacio y tiempo en la prehistoria santiagueña". Relaciones VIII, pp. 199-236.

Lorandi, A. M. 1978: "El desarrollo cultural prehispánico en Santiago del Estero, Argentina". Journal de la Société des Amèricanistes, LXV, pp. 61-85.

Lorandi, A. M. 2015: Tukuma-Tukuymanta. Los pueblos del búho. Santiago del Estero antes de la Conquista. Subsecretaría de Cultura, Santiago del Estero.

Manzanilla, L. (ed.) 1986: Unidades habitacionales mesoamericanas y sus áreas de actividad. UNAM, D. F. de México.

Martínez, A. T., Taboada, C. y Auat, A. 2008: "The Wagner brothers: French archaeologists and original myths in early 20th century Argentina", en Schlanger y Nordblandh (eds.), Archives, Ancestors, Practices. Archaeology in the Light of its History, Cap. 20, pp. 261-272. Bergham Books, Oxford.

Martínez, A. T., Taboada, C. y Auat, A. 2011: Los hermanos Wagner: entre ciencia, mito y poesía. Arqueología, campo arqueológico nacional y construcción de identidad en Santiago del Estero (1920-1940). Universidad Nacional de Quilmes, Buenos Aires.

Netting, R., Wilk, R. y Arnould, E. (eds.) 1984: Households: comparative and historical studies of the domestic group. University of California Press, Berkeley.

Nielsen, A. 1995: "Architectural performance and the reproduction of social power", en Skibo, Walker y Nielsen (eds.), Expanding Archaeology, pp. 47-66. University of Utah Press, Salt Lake City.

Nielsen, A. 2001: "Evolución del Espacio Doméstico en el Norte de Lípez (Potosí, Bolivia) ca. 900-1700 d.C.”. Estudios Atacameños, 21, pp. 41-61.

Ochoa, M., Rostain, S. y Salazar, E. 1997: "Montículos precolombinos en el alto Upano". Cultura, segunda época 2, pp. 54-61.

Ortiz, G. y D. Fernández. 2014: "Los sistemas de información geográfica aplicados al estudio de sitios arqueológicos en la cuenca media del río Salado, Santiago del Estero", en Armella, López y Seiffe (eds.), Actas y resúmenes de las $1^{\circ}$ Jornadas en Ciencias Naturales, pp. 30. Universidad Nacional de Tucumán, San Miguel de Tucumán.

Pestana, M. 2013: “A tradicao vieira e as estruturas monticulares na várzea do arroio Candiota, campanha do Rio Grande Do Sul, Brasil". Tempos Academicos, 11, pp. 84-96.

Politis, G. 1996: "Moving to produce: Nukak mobility and settlement patterns in Amazonia". World Archaeology, 27, pp. 492-510.
Politis, G. 2004: "Tendencias de la etnarqueología en América Latina”, en Politis y Peretti (eds.), Teoría arqueológica de América del Sur. Serie teórica $\mathrm{N}^{\circ} 3$, pp. 85-118. INCUAPA, Olavarría.

Prümers, H. y Jaimes Betancourt, C. 2014: "100 años de investigación arqueológica en los Llanos de Mojos". Arqueoantropológicas, año 4, $\mathrm{N}^{\circ} 4$, pp. 11-54.

Reichlen, H. 1940: "Recherches Archéologiques dans la Province de Santiago del Estero (Rép. Argentine)". Journal de la Societé des Amèricanistes, LXV, pp. 133-225.

Relaciones. 1940: "Los aborígenes de Santiago del Estero". Sociedad Argentina de Antropología, Buenos Aires.

Rostain, S. 1999: "Secuencia arqueológica en montículos del valle del Upano en la Amazonía ecuatoriana". Bulletin de l'Institut Français d'Études Andines, 28 (1), pp. 1-37.

Rostain, S. 2006: "Etnoarqueología de las casas Huapula y Jíbaro". Bulletin de l'Institut Français d'Études Andines, 35 (3), pp. 337-346.

Rostain, S. 2011: "Los edificadores de la selva: obras precolombinas en Amazonía". Por donde hay soplo, Actes \& Mémoires, 29, pp. 69-87. IFEA, Lima.

Schiffer, M. 1972: "Archaeological Context and Systemic Context". American Antiquity, 37, pp. 156-165.

Serrano, A. 1938: La Etnografia Antigua de Santiago del Estero y la llamada Civilización Chaco-Santiagueña. Editores Casa Predassi, Paraná.

Seymour, C. y Schiffer, M. 1987: "A preliminary analysis of pithouse. Assemblages from Snaketown. Arizona", en Kent (ed.), Method and theory for activity area research. An Etnoarchaeological Approach, pp. 549-603. Columbia University Press, New York.

Sillar, B. 2000: Shaping Culture. Making pots and Constructing Households. An Ethnoarchaeological Study of Pottery Production, Trade and Use in the Andes. BAR International Series, 883. British Archaeological Report, Oxford.

Stanish, C. 1989: "Household archaeology: Testing models of zonal complementarity in the south-central Andes". American Anthropologist, 91 (1), pp. 7-24.

Steadman, S. 1996: "Recent Research in the Archaeology of Architecture: Beyond the Foundations". Journal of Archaeological Research, 4 (1), pp. 51-93.

Stevanovic, M. 1997: "The Age of Clay: The Social Dynamics of House Destruction". Journal of Anthropological Archaeology, 16, pp. 334-395.

Taboada, C. 2005: "Propuesta metodológica para el análisis diacrónico de arquitectura prehispánica y la asignación de significado conductual discriminado. Aplicación en el Noroeste Argentino". Anales del Museo de América, 13, pp. 139-172.

Taboada, C. 2010: "Evolución del grupo doméstico corresidente y lógica social en la construcción, remodelación y uso del espacio habitacional”, en Albeck, Scattolin y Korstanje (eds.), El hábitat prehispánico. Arqueología de la arquitectura y de la construcción del espacio organizado, pp. 343264. EDIUNJU, Jujuy.

Taboada, C. 2014: "Sequía Vieja y los Bañados de Añatuya en Santiago del Estero. Nodo de desarrollo local e interacción macrorregional". Comechingonia, 18, pp. 93-116.

Taboada, C. 2016: "Espacio, cultura material y procesos sociales en la llanura santiagueña", en prensa en Cremonte, Ventura y Ortiz (eds.), Arqueología y Etnohistoria de la Vertiente Oriental de los Andes. EDUNJU, San Salvador de Jujuy.

Taboada, C. y Angiorama, C. 2010: "Metales, textiles y cerámica. Tres líneas de análisis para pensar una vinculación entre los habitantes de la llanura santiagueña y el Tawantinsuyu". Memoria Americana, 18 (2), pp. 11-41.

Taboada, C., Angiorama, C., Leiton, D. y López Campeny, S. 2013: "En la llanura y los valles...Relaciones entre poblaciones de las tierras bajas santiagueñas y el estado inca". Intersecciones en Antropología, 14, pp. 137-156.

Taboada, C. y Farberman, J. 2014: “Asentamientos prehispánicos y pueblos de indios coloniales sobre el rio Salado (Santiago del Estero, Argentina)”. Revista Latinoamericana de Arqueología Histórica, 8 (1), pp. 7-44.c

Von Hauenschild, J. 1949: "Ensayo de clasificación de la documentación arqueológica de Santiago del Estero". Revista de la Universidad Nacional de Córdoba, XXXVI, pp. 7-75. 
Wagner, E. y Wagner, D. 1934: La Civilización Chaco-Santiagueña y sus correlaciones con las del Viejo y Nuevo Mundo, Tomo I. Compañía Impresora Argentina, Buenos Aires.

Wilk, R. y Ashmore, W. 1988: Household and community in the mesoamerican past. University of New Mexico Press, Albuquerque.
Wilk, R. y Rathje, W. 1982: "Household archaeology". American Behavioral Scientist, 25 (6), pp. 617-639.

Zeidler, J. 1983: "La etnoarqueología de una vivienda Achuar y sus implicaciones arqueológicas". Miscelánea Antropológica Ecuatoriana, 3, pp. 155-193. 